\title{
əFuture Changes in Wet and Dry Season Characteristics in CMIP5 and CMIP6 Simulations $\mathscr{O}$
}

\author{
CARoline M. WAinwright, ${ }^{\mathrm{a}, \mathrm{b}}$ Emily Black, ${ }^{\mathrm{a}, \mathrm{b}}$ AND Richard P. Allan ${ }^{\mathrm{a}, \mathrm{c}}$ \\ ${ }^{a}$ Department of Meteorology, University of Reading, Reading, United Kingdom \\ ${ }^{\mathrm{b}}$ National Centre for Atmospheric Science, United Kingdom \\ ${ }^{\mathrm{c}}$ National Centre for Earth Observation, Reading, United Kingdom
}

(Manuscript received 29 January 2021, in final form 24 June 2021)

\begin{abstract}
Climate change will result in more dry days and longer dry spells; however, the resulting impacts on crop growth depend on the timing of these longer dry spells in the annual cycle. Using an ensemble of Coupled Model Intercomparison Project phase 5 and phase 6 (CMIP5 and CMIP6) simulations, and a range of emission scenarios, here we examine changes in wet and dry spell characteristics under future climate change across the extended tropics in wet and dry seasons separately. Delays in the wet seasons by up to 2 weeks are projected by 2070-99 across South America, southern Africa, West Africa, and the Sahel. An increase in both mean and maximum dry spell length during the dry season is found across Central and South America, southern Africa, and Australia, with a reduction in dry season rainfall also found in these regions. Mean dry season dry spell lengths increase by 5-10 days over northeast South America and southwest Africa. However, changes in dry spell length during the wet season are much smaller across the tropics with limited model consensus. Mean dry season maximum temperature increases are found to be up to $3^{\circ} \mathrm{C}$ higher than mean wet season maximum temperature increases over South America, southern Africa, and parts of Asia. Longer dry spells, fewer wet days, and higher temperatures during the dry season may lead to increasing dry season aridity and have detrimental consequences for perennial crops.
\end{abstract}

KEYWORDS: Precipitation; Rainfall; Climate change; Seasonal cycle; Seasonal variability; Extreme events

\section{Introduction}

Climate change will result in more dry days and longer dry spells; this has the potential to lead to negative impacts on crop yields and food security, as water stress limits crop growth. Across the tropics most crops are grown solely during the annual wet season, with few crops grown during the dry season. Therefore, the timing of these longer dry spells in the annual cycle is of crucial importance in determining their impact.

As the climate warms, the contrasting constraints of energy budgets at global scales and moisture budgets at regional scales drive a general increase in precipitation intensity and decrease in frequency that are further altered as atmospheric circulation patterns shift in location (Trenberth 2011; Held and Soden 2006; Funk et al. 2019; Giorgi et al. 2019; Allan et al. 2020). A larger increase in precipitation intensity compared to mean precipitation is balanced by a decrease in the number of wet days, resulting in longer dry spells and shorter wet spells (Giorgi et al. 2011; Seneviratne et al. 2012; Sillmann et al. 2013b). These longer dry spells may have negative impacts on crop yields and food production (Rockström et al. 2010), as

\footnotetext{
๑ Denotes content that is immediately available upon publication as open access.
}

Supplemental information related to this paper is available at the Journals Online website: https://doi.org/10.1175/JHM-D-210017.s1.

Corresponding author: Caroline M. Wainwright, c.wainwright@ reading.ac.uk reductions in water availability limit crop growth. Heavier rainfall events punctuating longer dry spells can also affect hydrological characteristics; for example, more rainfall can be taken up by the soil rather than producing runoff, yet on the other hand, more intense rainfall falling on encrusted ground can lead to higher runoff (Eekhout et al. 2018; Yin et al. 2018).

Many studies have reported an increase in the number of dry days and dry spell lengths under future climate change. Giorgi et al. (2019) found an increase in the number of dry days and dry spell lengths and a decrease in wet spell lengths aggregated over land areas in the tropics and the extratropics over the twenty-first century in 10 Coupled Model Intercomparison Project phase 5 (CMIP5) model projections. Giorgi et al. (2014) report that the response in wet and dry spell lengths is more pronounced and spatially consistent over the tropics than the extratropics. Polade et al. (2014) also identified an increasing dry day frequency, in particular over northern South America, Central America, southern Africa, and the Mediterranean-regions also identified by Pascale et al. (2016) as showing increases in the number of dry days. While Giorgi et al. (2014) and Giorgi et al. (2019) examined the mean wet and dry spell lengths over large land areas, Sillmann et al. (2013b) looked at the maximum wet and dry spell lengths over a number of regions. They find significant increases in maximum dry spell length over Central America, parts of South America, the Mediterranean, southern Africa, and South and Southeast Asia [consistent with the regions where Polade et al. (2014)

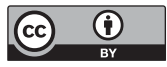

This article is licensed under a Creative Commons Attribution 4.0 license (http://creativecommons.org/ licenses/by/4.0/). 
found more dry days], with decreases in maximum dry spell length over the high northern latitudes, northeast Asia, and East Africa. Lau et al. (2013) also suggest increasing dry spell lengths over southern Africa, the Mediterranean, and parts of South America, although they use a threshold of $<0.024 \mathrm{~mm}$ day $^{-1}$ to look at the changes in the frequency of dry months. Overall, the Intergovernmental Panel on Climate Change (IPCC) Special Report on Extremes concluded that an increase in dry spell length and frequency was very likely over the Mediterranean and southern Australia, and likely over most subtropical regions (Seneviratne et al. 2012).

Most of these previous studies have looked at changes in wet and dry spells across the entire calendar year (Sillmann et al. 2013b). In the tropics, however, most crops are grown during the annual wet season. Therefore, the impact of longer or shorter wet and dry spells may vary throughout the year. Longer dry spells during the main wet season may have significant detrimental impacts on agriculture, whereas longer dry spells within the period of the year that is climatologically dry may have less impact. Conversely, longer wet spells within the dry season may be beneficial, e.g., for recharging water supplies. Therefore, understanding the timing of changes in wet and dry spell lengths is of crucial importance. Orlowsky and Seneviratne (2012) looked at changes in consecutive dry days (CDD) in the four meteorological seasons and found some differences in the projected changes in different seasons; for example, over Asia there is a decrease in CDD in DecemberFebruary (DJF), but an increase in June-August (JJA). The magnitude of changes was also different in different seasons; for example, over southern Africa the increase in CDD was greater in JJA than in DJF. However, these 3-month meteorological seasons may not map directly onto wet and dry seasons and there may be changes in wet and dry season length in the future (Dunning et al. 2018). Other studies looking at changes in wet and dry spell lengths in wet seasons have focused over certain regions, for example, Klutse et al. (2018) looked at changing wet and dry spell lengths in June-September over West Africa, and Mba et al. (2018) examined changing wet and dry spell lengths in March-May and September-November over Central Africa. Furthermore, very few studies have also considered the impact of temperature changes; increases in temperature combined with longer dry spells may lead to reductions in soil moisture and increased water stress for crops. Changes in extreme temperatures may differ in wet and dry seasons, hence it is important to separately examine the wet and dry seasons, so as not to exaggerate the impact of temperature changes on agriculture.

Although the seasonal timing of changes in wet and dry spells is of significant societal importance, it has not been investigated consistently in previous studies. Many studies have found a trend of wet seasons getting wetter and dry seasons getting drier under future climate change (Chou et al. 2013; Kumar et al. 2015; Schurer et al. 2020), suggesting there may be notable seasonal differences in wet and dry spell projections. Thus, the aim of the present study is to answer the question "Do changes in the length of wet and dry spells differ in climatologically wet and dry seasons?" Unlike previous dry spell studies, a recently developed methodology is used to determine the timing of the wet and dry season at each location (Liebmann et al. 2012; Dunning et al. 2016), thus enabling investigation of changes in the wet and dry season using a location-specific, not month-based, seasonal definition. Furthermore, we utilize projections from the latest version of coupled global climate models, which have recently been released [Coupled Model Intercomparison Project phase 6 (CMIP6); Eyring et al. 2016]; these are of higher resolution with more complex models than the previous generation of coupled global climate models (CMIP5; Taylor et al. 2012), and thus represent a new opportunity for exploring changes in daily quantities. Here, results from both CMIP5 and CMIP6 are compared, using a range of emissions scenarios. Many previous studies have used the well-established Climdex (https://www.climdex.org/) indices to explore changes in wet and dry spells (Zhang et al. 2011; Seneviratne et al. 2012; Sillmann et al. 2013b). These define CDD (consecutive dry days; maximum length of dry spell) and CWD (consecutive wet days; maximum length of wet spell) as "the maximum number of consecutive days with daily precipitation less than/greater than $1 \mathrm{~mm} \mathrm{day}^{-1}$ " (for CDD/CWD, respectively). This therefore only looks at the longest wet/dry spell in a year. In this study we aim to look at a more complete set of metrics, including number of wet days and mean length of wet/dry spells, to gain a more complete picture of how wet and dry spells are changing under future climate change. Along with changes in wet and dry spells, changes in maximum temperatures are also considered, as large temperature increases may exacerbate the impacts of long dry spells.

\section{Data and methodology}

\section{a. Model data}

Daily precipitation data were used from 31 CMIP5 (Taylor et al. 2012) models and 19 CMIP6 (Eyring et al. 2016) models under a medium [Representative Concentration Pathway (RCP) 4.5/Shared Socioeconomic Pathway (SSP) 245] and high (RCP8.5/SSP585) emissions scenario; a full list of models used is included in Tables S1 and S2 in the online supplemental material. SSP585 is the highest emissions scenario and represents an update to the RCP8.5 emissions scenario (the highest emission scenario for CMIP5); both produce a radiative forcing of $8.5 \mathrm{~W} \mathrm{~m}^{-2}$ in 2100 (Van Vuuren et al. 2011; O'Neill et al. 2016). While some have argued that this pathway is unrealistic, it should be noted that current emissions are in line with the RCP8.5 scenario (Schwalm et al. 2020). The SSP245 scenario represents a medium emissions scenario and updates the RCP4.5 pathway; both produce a radiative forcing of $4.5 \mathrm{~W} \mathrm{~m}^{-2}$ in 2100 (Van Vuuren et al. 2011; O’Neill et al. 2016).

Models were selected based on the availability of daily precipitation data for historical and RCP4.5/RCP8.5 (CMIP5) or SSP245/SSP585 (CMIP6) simulations for periods at the end of the twentieth and twenty-first centuries. For the present-day climate, the historical simulation was used over the period 1 January 1985-31 December 2014, chosen to be in line with IPCC AR6. For the CMIP5 simulations the historical simulation is only available until 31 December 2005; CMIP5 RCP4.5 simulations were used for 1 January 2006-31 December 2014 
(taken from the same model) and appended to the historical simulations for 1 January 1985-31 December 2005. Recent analysis suggests that $\mathrm{CO}_{2}$ emissions have been above RCP4.5 levels over the recent period, so this gives a conservative estimate (Schwalm et al. 2020). Projections from RCP4.5 and RCP8.5 do not differ significantly over this 2005-14 period, therefore the choice of scenario was assumed to have a minimal impact. Furthermore, the primary focus is on the newer CMIP6 models; results from the CMIP5 models are mainly presented for traceability with previous studies. The period 1 January 2070-31 December 2099 was used for the end of the twentyfirst century period. Only the first ensemble members were used (r1i1p1/r1i1p1f1) - for two CMIP6 models r1i1p1f2 was used due to r1i1p1f1 being unavailable (see Table S2). Other studies have taken a similar approach. Daily maximum temperature data were also used for the same set of models and time periods, however, they were unavailable for a couple of the models at the time when the analysis was conducted; this is indicated in Table S2.

Data were considered over the region $50^{\circ} \mathrm{S}-50^{\circ} \mathrm{N}$. The focus here is on differences in wet and dry seasons so the decision was taken to focus on this tropics and subtropics region that has a well-defined wet season (equatorward parts of midlatitudes are also included in $50^{\circ} \mathrm{S}-50^{\circ} \mathrm{N}$ ); high-latitude regions tend to have less well-defined wet and dry seasons and thus are not included. All analysis was done on the models at native resolution. For the multimodel median maps the metrics were first computed at the native resolution and were then regridded onto the lowest-resolution grid using nearest-neighboring remapping. For the regional analysis the regions were calculated for each model grid and the model's native resolution grid was used.

\section{b. Observational data}

CHIRPS (Climate Hazards Group Infrared Precipitation with Stations) precipitation data were used over $50^{\circ} \mathrm{S}-50^{\circ} \mathrm{N}$ for 1 January 1985-31 December 2014 (to be comparable to historical CMIP6 simulations). CHIRPS precipitation estimates use thermal infrared imagery and gauge data in addition to a monthly precipitation climatology, CHPClim (Climate Hazards Center's Precipitation Climatology) and CFS (Coupled Forecast System) version 2 reanalysis fields to produce rainfall estimates (Funk et al. 2015).

\section{c. Methodology}

To calculate metrics, including mean wet and dry spell lengths, for wet and dry seasons separately, each grid point is first classified into one of four seasonality categories (section 1), then season start and end dates are computed using a methodology for objectively calculating wet season onset and cessation dates (section 2). Metrics are then calculated for wet and dry seasons separately (section 3 ).

\section{1) SEASONALity ClASSIFICATION}

The seasonality of precipitation varies across the tropics from monsoonal regions with one summer wet season per year, to dry desert regions with little rainfall, to rain forest regions that are wet year-round. East Africa is known to experience two wet seasons per year (Yang et al. 2015). To distinguish between wet and dry seasons, it is first important to determine the seasonal regime.

A number of different methodologies have been utilized for this purpose; Herrmann and Mohr (2011) used monthly precipitation and temperature to define rainfall seasonality regimes across Africa. Pascale et al. (2016) and Feng et al. (2013) used the relative entropy and dimensionless seasonality index to define and examine changes in the "Global Monsoon Domain." Liebmann et al. (2012) and Dunning et al. (2016) use harmonic analysis to separate regions with one or two wet seasons per year across Africa. A combination of these metrics is used here.

It was decided that four categories need to be distinguished: regions that are dry year-round, regions that are wet yearround, regions with one wet season per year (annual regime), and regions with two wet seasons per year (biannual regime). While Herrmann and Mohr (2011) defined additional regimes, here just four are used for simplicity. The methodology used has three steps:

1) The mean annual rainfall was computed at each land grid point (between $50^{\circ} \mathrm{S}$ and $50^{\circ} \mathrm{N}$ ). The $20 \%$ of driest land grid points were excluded as dry regions with no marked wet season.

2) Grid points with a relative entropy (a measure of how uniform or variable the seasonal sequence of monthly rainfall is, see below) less than 0.3 were defined as wet year-round with no marked wet/dry seasons.

3) The remaining grid points were defined as having one/two wet seasons per year based on the ratio of the amplitude of the second harmonic to the amplitude of the first harmonic. If the ratio is greater than $1 /$ less than 1 then the grid point experiences a biannual/annual regime with two/one wet season(s) per year.

The relative entropy $\left(D_{k}\right)$ quantifies how different the observed sequence of monthly rainfall is from a uniform monthly sequence with unchanging monthly rainfall. The relative entropy attains the maximum value when the annual rainfall is concentrated in one single month, and equal to 0 for a uniform precipitation sequence (Feng et al. 2013; Pascale et al. 2016). Details of the calculation of relative entropy are in the supplementary information.

Regions that are wet year-round have a low value of relative entropy. Pascale et al. (2016) defined the Global Monsoon Domain to be where $D_{k}>0.4$ (and where the dimensionless seasonality index is $>0.05$, but this is mainly used to remove dry regions), but when examining changes in the timing of the rainfall centroid Pascale et al. (2016) used a relative entropy threshold of 0.3 to "exclude regions without a pronounced dry season." Here a threshold of 0.3 is used; a range of thresholds were considered, and it was decided that a $D_{k}$ threshold of 0.3 classified regions such as the Maritime Continent, Central Africa, and eastern North America, known to be wet yearround, correctly, while also classifying most of South America as having an annual regime. The aim was to just exclude those points that are definitely wet year-round (without a pronounced dry season), as opposed to just including those with a well-defined monsoon, hence the threshold of 0.3 was used. 

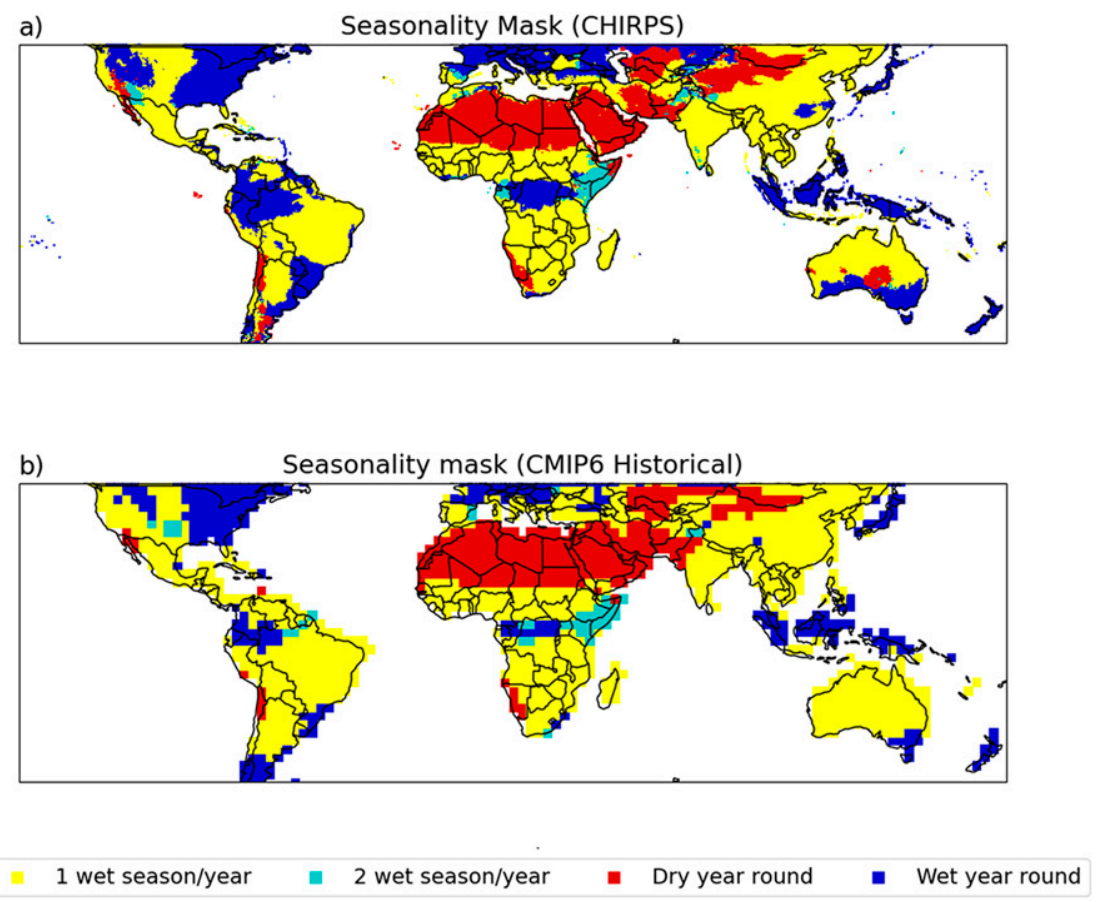

FIG. 1. (a) Seasonality mask produced using CHIRPS rainfall data over 1985-2014. (b) CMIP6 multimodel modal seasonality mask for the historical simulation over 1985-2014. Red indicates dry year-round, blue indicates wet year-round, yellow indicates one wet season per year, and pale blue indicates two wet seasons per year. See Fig. S1 for CMIP5 and other scenarios.

The seasonality classification for CHIRPS (Fig. 1) shows that the dry desert regions (including the Sahara and Gobi Deserts and the Arabian Peninsula) are correctly identified as dry year-round, central equatorial Africa and the Maritime Continent are correctly identified as wet year-round, and the Horn of Africa is categorized as biannual. Monsoon regions, such as India, East Asia, and South America, are correctly identified as experiencing an annual regime. Over Africa, the classification is similar to that produced by Herrmann and Mohr (2011). This classification gives an overall picture-in regions of complex rainfall regimes, with multiple rainfall peaks separated by a relatively drier period lasting only 1-2 months (e.g., Central America; Small et al. 2007) it may not capture this complex seasonal regime, and defines the region as having one wet season per year.

The seasonality classification was calculated for each model and scenario; it was calculated separately for the present and future periods. Figure 1 shows the seasonality mask for CHIRPS, and the modal seasonality classification for CMIP6 historical (for CMIP5 and all scenarios see Fig. S1). For the most part the model seasonality classification shows good agreement with CHIRPS with a few minor differences; southern Australia and eastern China are shown as having one wet season in models whereas they are defined as wet yearround in observations. In terms of the future projections there are not large changes in the overall pattern of seasonality ( $<10 \%$ of grid points change regime), and most changes are located on regime boundaries (Fig. S1). The notable changes are over southern Europe/the Middle East, where we see changes from wet year-round to an annual regime, and over Central Africa CMIP6 shows some grid points change from wet year-round to two wet seasons per year, presumably due to larger rainfall increases in the wetter seasons than the drier seasons.

\section{2) WET AND DRY SEASON DISTINCTION}

The method of anomalous accumulation was used to determine start and end dates of the climatological wet and dry seasons. This method is suitable for application at a global scale as it does not use a set precipitation threshold, and therefore can be applied to regions with very different rainfall amounts (Liebmann et al. 2012; Dunning et al. 2016). It is applicable to regions with both one and two wet seasons per year (Dunning et al. 2016). Full details of the calculation can be found in the supplementary information.

Onset and cessation dates were calculated for each model and scenario, thus accounting for changing seasonal timing under future climate change. Historical patterns of onset and cessation in the CMIP5 and CMIP6 models were similar to those produced using observations, with a wet season during the boreal summer in the Northern Hemisphere and a wet season during the austral summer in the Southern Hemisphere (see Figs. S2-S6 in the supplementary information); Dunning et al. (2017) showed that CMIP5 models generally captured the correct patterns of onset and cessation across Africa, when assessed using this methodology. 

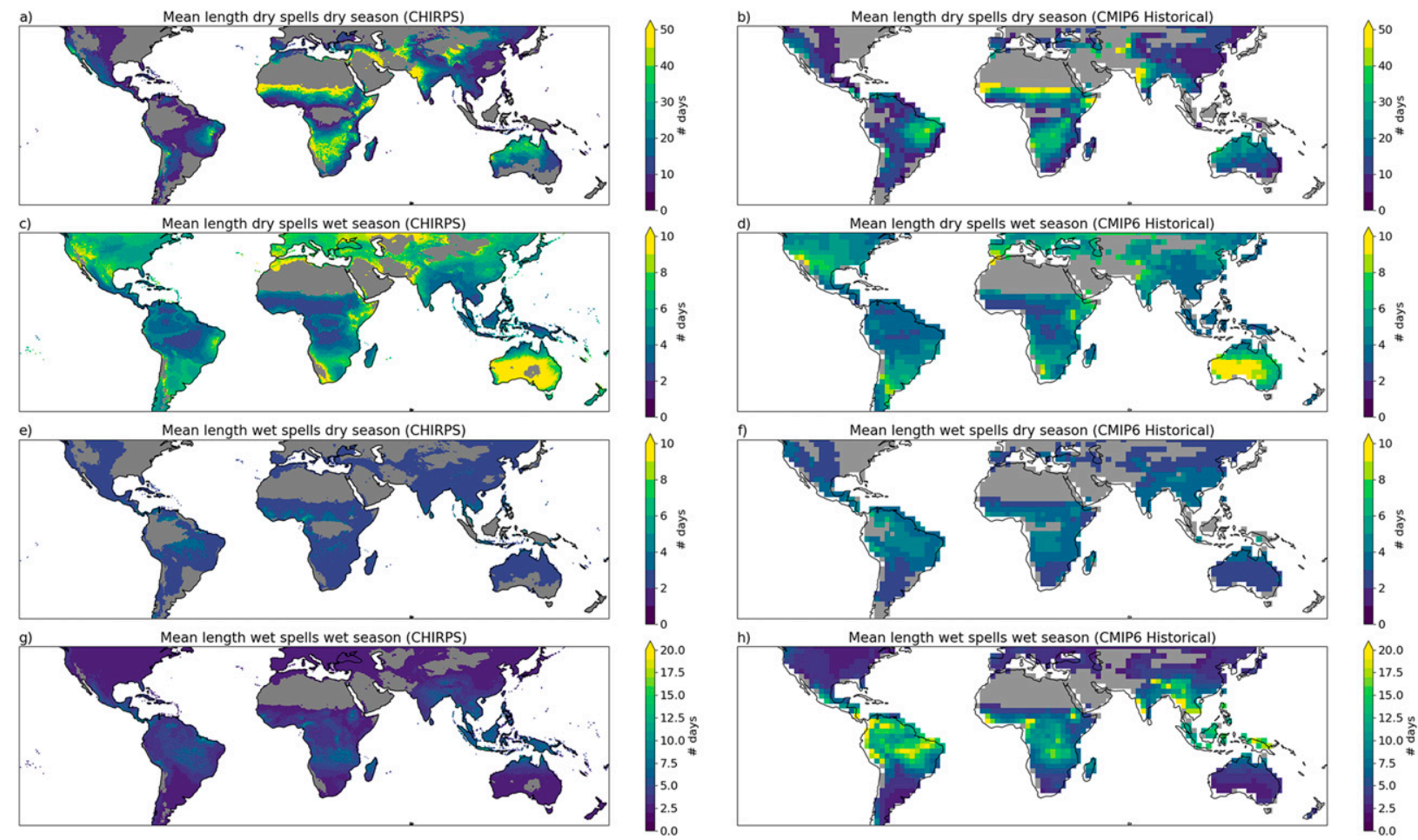

FIG. 2. Mean length of (a),(b) dry spells in the dry season, (c),(d) dry spells in the wet season, (e),(f) wet spells in the dry season, and (g),(h) wet spells in the wet season from (left) CHIRPS and (right) the multimodel median of the CMIP6 historical simulations. The period 1985-2014 is used for both CHIRPS and CMIP6. Gray regions indicate where at least 50\% of the models do not give a value (dry year-round or wet year-round in the dry season plots), or where CHIRPS is wet year-round or dry year-round.

\section{3) WET AND DRY SPELL METRICS}

A range of metrics were calculated for wet and dry seasons. The wet season was defined to be the period after the onset and before the cessation date, while the dry season was defined to be the period between the cessation date and the onset date. For the metrics calculated here, a threshold of $1 \mathrm{~mm} \mathrm{day}^{-1}$ was used to define a wet/dry day. The well-established Climdex indices also use a threshold of $1 \mathrm{~mm} \mathrm{day}^{-1}$ to define wet/dry days for the calculation of CWD and CDD, used in Seneviratne et al. (2012) and Sillmann et al. (2013b). Other studies looking at wet and dry days and spells also use a threshold of $1 \mathrm{~mm}^{\text {day }}{ }^{-1}$ (Polade et al. 2014; Giorgi et al. 2014; Funk et al. 2019; Giorgi et al. 2019), and this is confirmed by analysis of cumulative frequency of daily rainfall (Fig. S7).

The following metrics were calculated:

- Wet/dry season rainfall: Sum of daily rainfall over the wet/dry season.

- Wet/dry season rainy days: The number of days with rainfall greater than $1 \mathrm{~mm} \mathrm{day}^{-1}$ in the wet/dry season.

- Wet/dry season rain per rainy day: The mean rainfall over all days with rainfall greater than $1 \mathrm{~mm}$ day $^{-1}$ in the wet/dry season.

- Maximum wet/dry spell length in wet/dry seasons: The length (in days) of the longest wet/dry spell in each wet/dry season.

- Mean wet/dry spell length in wet/dry seasons: The mean length (in days) of all wet/dry spells (of length 2 days or more) in the wet/dry season.
- Wet/dry season mean maximum temperature: The mean of the daily maximum temperature over the wet/dry season.

Metrics were computed for one wet season for the annual regime region and for two wet seasons for the biannual regime regions. For the wet-year-round regions the metrics were calculated for each calendar year (wet season was assumed to last all year); these points have a wet season but no dry season, so are included in wet season plots but not dry season plots. The median was taken over all seasons and the historical and future periods compared. For the maps, the change was regridded onto the lowest resolution model using nearest-neighbor remapping.

Figures 2 and S8 show that the historical simulations from the CMIP5 and CMIP6 models capture the observed distribution of wet and dry spells in wet and dry seasons as found in CHIRPS. The main difference is the mean length of wet spells in the wet season where the CMIP6 models contain much longer wet spells than the observations. Similarly, Sillmann et al. (2013a) found good model representation of CDD in the CMIP5 models, but found that CWD was overestimated in both models and reanalyses. Results from a second observational dataset [Multi-Source Weighted-Ensemble Precipitation (MSWEP; Beck et al. 2019); Fig. S9] are very similar to those shown in Fig. 2 for CHIRPS. The mean length of wet spells in the wet season is longer in MSWEP over parts of South America, Ethiopia, and the Himalayas in MSWEP, presumably due to 


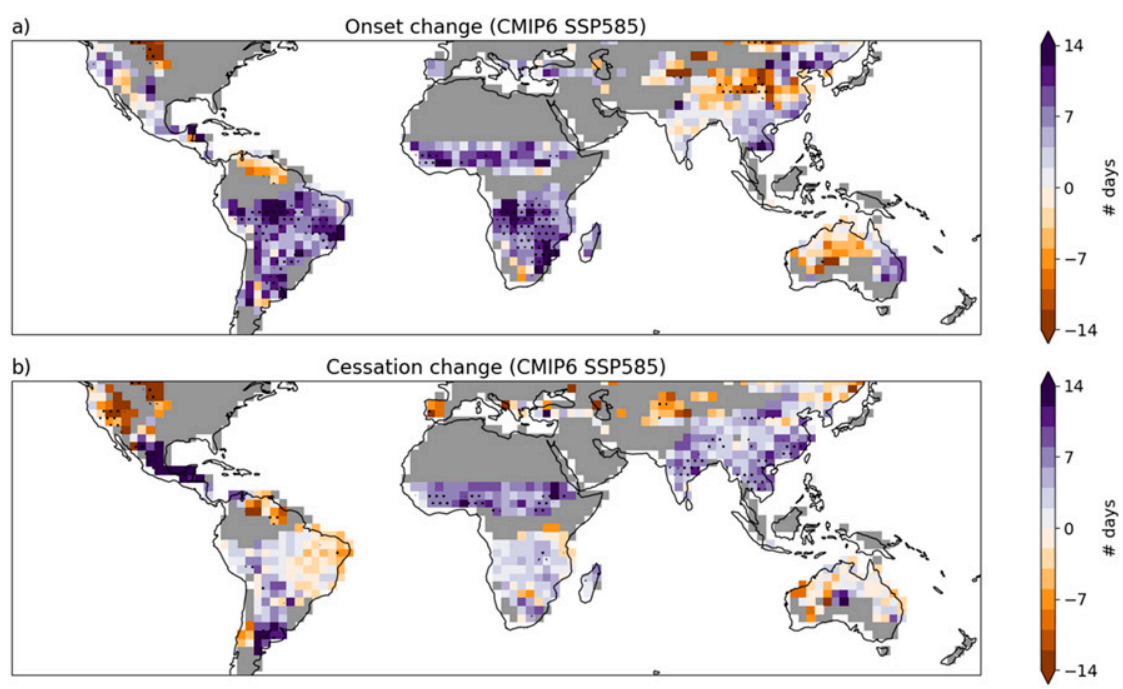

FIG. 3. CMIP6 multimodel median change in (a) onset of the annual wet season and (b) cessation of the annual wet season for the SSP585 scenario over 2070-99 compared with the historical simulation over 1985-2014. Purple indicates later while orange indicates earlier. Stippling indicates where $75 \%$ of the models agree on the sign of the median. Gray regions indicate where at least $50 \%$ of the models do not give a value (dry year-round/wet year-round/ biannual regime).

the inclusion of reanalysis data, but the mean lengths in CMIP6 still exhibit a positive bias over these regions when compared with MSWEP.

\section{4) REgions}

To explore changes over certain regions a regional classification was required. The regions used here are those defined for the sixth IPCC report (Iturbide et al. 2020). (The locations and regions used are shown in Figs. 6a, 8a, and 10a.)

\section{5) TIME SERIES ANALYsis}

Time series were produced for certain regions to examine the changes over the whole period (1985-2099). The regions for time series were selected over areas of particular interest, where significant changes in wet/dry spell length had been identified. For the time series it is assumed that all grid points have an annual regime; for the three regions used [northeast South America (NES), southeast Africa (SEAF), and West Africa (WAF)] this is a reasonable assumption (Fig. 1).

When calculating the time series of wet/dry spell lengths over the IPCC regions two methodologies were employed. The first methodology defined a climatological onset and cessation date using the full 115 years of the time series and then used the same onset and cessation date for each year, thus not accounting for changes in seasonal timing. The wet and dry spell lengths were then calculated for each year, in the same manner as above. The second methodology used a moving 30-yr period to calculate the onset and cessation dates, with the first 15 and last 15 years of the full record set to the first-30-years value and the last-30-years value. Thus, this second methodology takes into account changes in seasonal timing. In section 3 , time series produced using the second methodology were presented.
For the most part the differences between the two methodologies were similar.

\section{Results and discussion}

Results are presented here for wet and dry seasons; section 3a on seasonal timing presents changes in timing of the onset and cessation of the wet season, while sections $3 b-3 e$ present changes in rainfall and temperature metrics for wet and dry seasons separately. Figure S2 in the supplementary information indicates the timing of the wet season(s) in the calendar year for reference.

\section{a. Seasonal timing}

The multimodel median change in onset and cessation of the annual wet season in CMIP6 under the SSP585 scenario, shown in Fig. 3, shows that onset is projected to get later across South America, southern Africa, West Africa, and the Sahel, with changes of up to 2 weeks. Over South America this continues the recent trend of delayed onset found by Correa et al. (2020). Over East Asia Fig. 3 shows the onset is projected to be earlier, with advances of over a week in some locations. Changes in cessation are smaller than changes in onset; Fig. $3 \mathrm{~b}$ shows later cessation by up to a week over the Sahel, and parts of Asia, with the largest changes of around 2 weeks over central America. These results show good agreement with previous studies of changing onset over Africa (Dunning et al. 2018) and over Asia, with Kitoh et al. (2013) reporting a later retreat over South Asia and Ha et al. (2020) reporting an earlier onset over East Asia. The results also show good agreement with Pascale et al. (2016), who analyzed changes in the timing of the rainfall centroid, and found a delay over 

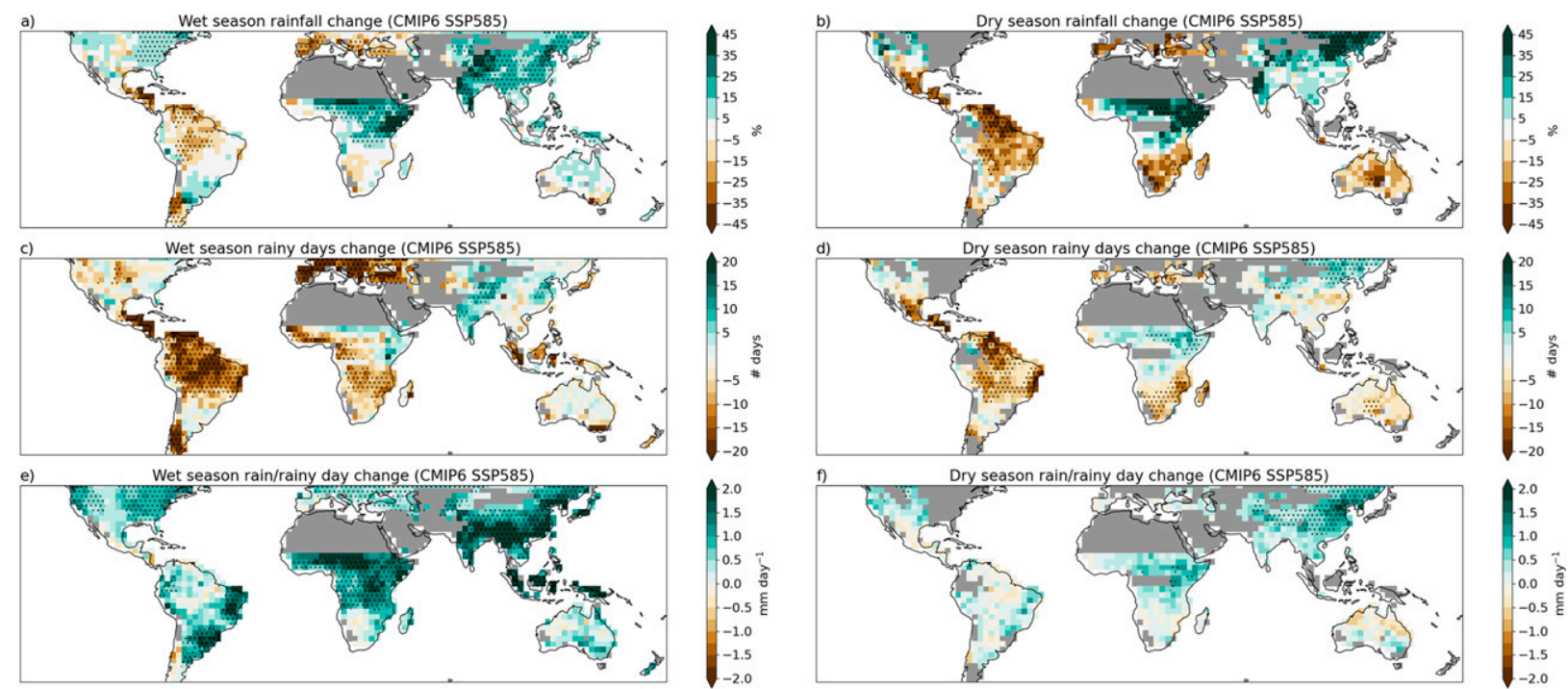

FIG. 4. CMIP6 multimodel median change in (a) wet season rainfall, (b) dry season rainfall, (c) number of rainy days in the wet season, (d) number of rainy days in the dry season, (e) wet season rain per rainy day, and (f) dry season rain per rainy day for the SSP585 scenario over 2070-99 compared with the historical simulation over 1985-2014. Stippling indicates where $60 \%$ of the models show a statistically significant change ( $t$ test, $10 \%$ significance level) of the same sign as the median change. Gray regions indicate where at least $50 \%$ of the models do not give a value (dry year-round or wet year-round in the dry season plots).

Africa, Central and South America, and parts of South Asia, with an advance over East Asia. More broadly, a number of studies have found a global phase delay of the seasonal cycle of precipitation (Biasutti and Sobel 2009; Dwyer et al. 2014; Marvel et al. 2017) and a redistribution of rainfall from early to late in the monsoon season (Seth et al. 2013), in agreement with the generally later onset/cessation shown in Fig. 3. A number of mechanisms have been proposed for this; Dwyer et al. (2014) linked the delay to changes in the seasonality of the circulation, Seth et al. (2013) linked the delay to an enhanced spring convective barrier, while Song et al. (2018) linked the delay to changes in cross-equatorial energy transports and change in the strength of the subtropical highs.

\section{b. Seasonal rainfall characteristics}

First, changes in seasonal rainfall totals, seasonal number of rainy days and seasonal rain per rainy day were explored; Fig. 4 shows the changes from CMIP6 under SSP585. South and East Asia, eastern Africa, and eastern North America all show projected increases in wet season rainfall (Fig. 4a); due to a combination of increasing rainfall intensity in the wet season (Fig. 4e) and either limited change or a slight increase in the number of wet days in the wet season (Fig. 4c). Wang et al. $(2021,2020)$ and Collins et al. (2013) also show an increase in boreal summer rainfall over South and East Asia; Wang et al. (2020) show increases of around $1 \mathrm{~mm} \mathrm{day}^{-1}$ in JJAS over South and East Asia. The Mediterranean, Central America, and northern South America exhibit significant decreases in wet season rainfall (of $5 \%-25 \%$, Fig. $4 \mathrm{a}$ ); these regions also experience a significant decrease in the number of rainy days in the wet season (decrease of over 15 days, Fig. 4c), and smaller increases in rain per rainy day (Fig. 4e). The asymmetry between the American and Asian-African monsoon systems, with the North American monsoon getting drier and the Asian-African monsoon getting wetter, identified in other studies (e.g., He et al. 2020), is apparent in Fig. 4. Other regions, including southern Africa, the Maritime Continent, and parts of southern Europe, also exhibit a decrease in the number of wet season rainy days (Fig. 4c). However, a significant decrease in rainfall is not found in these regions (Fig. 4a) as the decrease in the number of rainy days is compensated by an increase in rain per rainy day (Fig. 4e), broadly consistent with expectations from joint thermodynamic and energetic constraints (Allen and Ingram 2002; Trenberth 2011).

Considering the dry season, Central America, South America, southern Africa, and Australia all show decreases in dry season rainfall (Fig. 4b), decreases in the number of wet days in the dry season (Fig. 4d) and little change in dry season rain per rainy day (Fig. 4f). A decrease in boreal summer rainfall over southern Africa is also found by Wang et al. $(2021,2020)$ and Collins et al. (2013), and a number of studies have identified an increasing contrast between wet and dry seasons, with wet seasons getting wetter and dry seasons getting drier (Chou et al. 2013; Kumar et al. 2015; Polson and Hegerl 2017; Lan et al. 2019; Deng et al. 2020; Schurer et al. 2020). Eastern Africa, the eastern Sahel, and East Asia all show increases in dry season rainfall (Fig. 4b), increases in the number of dry season rainy days (Fig. 4d) and increases in dry season rain per rainy day (Fig. 4f). Rainfall increases over East Asia are in good agreement with Wang et al. (2021, 2020), and Collins et al. (2013) who identified increased boreal winter rainfall in this region. In general, the increases in dry season rain per rainy day are less than the increases in wet season rain per rainy day. Changes in seasonal rainfall are shown as a percentage of the wet/dry season rainfall; thus, while changes in dry season rainfall may appear larger, in absolute terms the changes in wet 

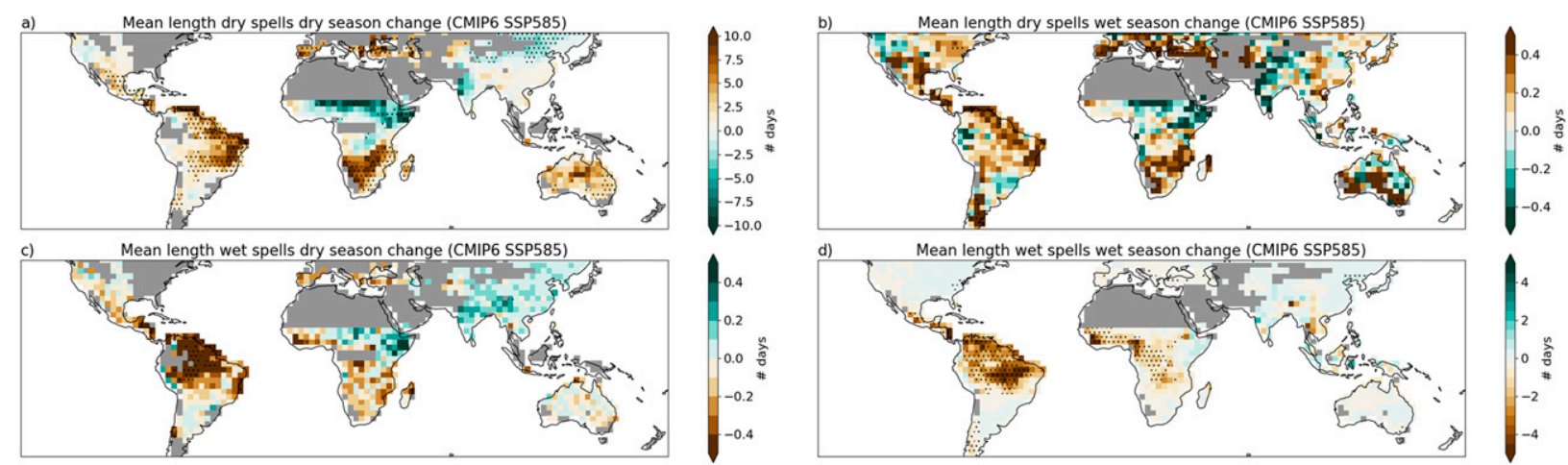

FIG. 5. CMIP6 multimodel median change in (a) mean length of dry spells in the dry season, (b) mean length of dry spells in the wet season, (c) mean length of wet spells in the dry season, and (d) mean length of wet spells in the wet season for the SSP585 scenario over 2070-99 compared with the historical simulation over 1985-2014. Stippling indicates where $60 \%$ of the models show a statistically significant change ( $t$ test, $10 \%$ significance level) of the same sign as the median change. Gray regions indicate where at least $50 \%$ of the models do not give a value (dry year-round or wet year-round in the dry season plots).

season rainfall are larger. Central and northern South America show rainfall decreases in both seasons, in agreement with Wang et al. (2020) who also show precipitation decreases over the region in boreal summer and winter, although in winter they find increases over the east and west coast, although it should be noted that they use a month-based seasonal definition, and the increases are very close to the coast, which may have been removed in the land-sea mask applied here.

Changes from CMIP6 under SSP245 and from CMIP5 under RCP8.5 (Figs. S10 and S11) were generally of the same sign of those shown in Fig. 4, but of lower magnitude, possibly related to the higher climate sensitivity in CMIP6 than in CMIP5 (Meehl et al. 2020). Over northern South America decreases in dry season rainfall were ubiquitous, but decreases in wet season rainfall were only found in CMIP6 under SSP585. Although they all show a decrease in the number of wet season rainy days over northern South America, CMIP5 RCP8.5 shows a larger increase in wet season rain per rainy day, and CMIP6 SSP245 has a smaller decrease in the number of rainy days, but similar change in rain per rainy day to CMIP6 SSP585. Increases in wet season rainfall over eastern Africa and South and East Asia, and increases in dry season rainfall over East Africa and East Asia, were found to be robust across the three scenarios and CMIP eras. Decreases in dry season rainfall over southern Africa were present in all three scenarios and CMIP eras, but were only significant under SSP585 and RCP8.5.

\section{c. Wet and dry spells}

Figure 5 shows the projected changes in the mean length of wet and dry spells in wet and dry seasons from CMIP6 under SSP585; the changes in maximum spell length are generally of the same sign and of larger magnitude (see Fig. S14).

During the dry seasons, projections indicate longer dry spells over Central America, northeast South America, southern Africa, and Australia, with increases of up to 10 days (Fig. 5a). This is consistent with Fig. 4 which showed reductions in dry season rainfall and fewer dry season rainy days over these regions. Shorter dry spells in the dry season are found over East Africa and parts of the Sahel and East Asia (Fig. 5a); these regions showed increases in dry season rainfall and more rainy days in the dry season (Fig. 4). Orlowsky and Seneviratne (2012) also show increases in CDD over southern Africa in JJA (local dry season). Over northern South America, Orlowsky and Seneviratne (2012) show increases in CDD in different regions in all four seasons, with the smallest increases in DJF (the peak of the wet season), thus agreeing on the projection of longer dry spells in the dry season, but also demonstrating the impact of different definitions of seasonality. Sillmann et al. (2013b) also show large increases in CDD over northeast South America, southern Africa, Australia, and central America.

For the mean length of dry spells in the wet season (Fig. 5b) the changes are generally very small (multimodel median is generally less than half a day) and not statistically significant. Only southern Europe and the northern Mediterranean shows a statistically significant increase in dry spell length in the wet season; the signal is also seen over the same region for dry seasons (Fig. 5a). Parts of the Mediterranean are classified as having one wet season per year, while other parts are wet yearround, thus Figs. 5a and 5b indicates a general increase in dry spell length in this region. Other studies, including Orlowsky and Seneviratne (2012) and Seneviratne et al. (2012) show increases in CDD in the Mediterranean, and Brogli et al. (2019) show year-round decreases in Mediterranean rainfall.

The changes in the mean length of wet spells are generally of smaller magnitude than the changes in the mean length of dry spells (Figs. 5c,d). The only statistically significant change in the mean length of wet spells in the dry season is over northern South America, which shows a decrease in the mean length of wet spells in the dry season; but the magnitude of the change is small (Fig. 5c). Only two regions show significant changes in the mean length of wet spells in the wet season (Fig. 5d); central and northern South America and West/Central Africa both show decreases of less than 5 days. These are the regions with the longest wet spells during the wet season in current climate (Fig. 2), and therefore are likely to exhibit the largest changes. These regions also show fewer wet season rainy days under future climate change (Fig. 4c), consistent with shorter wet spells. 
Again, changes from CMIP6 under SSP245 and from CMIP5 under RCP8.5 (Figs. S12, S13, S15, and S16) were generally of the same sign of those shown in Fig. 5, but of lower magnitude. For the mean length of dry spells in the dry season, increases were present across Central America, northeast South America, southern Africa, and Australia in all three scenarios and CMIP eras, but the magnitude and statistical significance was reduced, particularly under SSP245 where only southern Africa and small parts of South America showed a statistically significant increase. For the mean length of wet spells in the wet season, the signal was similar in CMIP5 RCP8.5 to CMIP6 SSP585, but much reduced in CMIP6 SSP245, with only the decrease over northern South America present.

Figure 3 showed changes in the length of wet and dry seasons under future climate change, which may affect the length of wet and dry spells. Therefore the analysis was repeated, calculating wet and dry spell lengths as a percentage of the wet/dry season length; results were similar, demonstrating that the changes found here are not a consequence of changing season lengths.

Overall, Figs. 5a and 5b indicates that the significant increases in dry spell length expected under future climate change are projected to occur during the dry season not the wet season. Only parts of the Mediterranean and southern Europe, where some locations experience rainfall year-round, show a significant increase in dry spell length in the wet season. Therefore, agriculture grown solely during the wet season may be less affected by longer dry spells. However, Figs. 4 and 5 indicate longer dry spells, fewer rainy days, and less rainfall during the dry season in certain regions, which may make the dry seasons more intense, negatively impacting perennial crops and crops grown during the dry season.

\section{d. Regional changes}

Figures 4 and 5 have presented changes across the tropics; three regions are now considered in more detail. Some of the largest changes in wet and dry spell lengths identified in Figs. 4 and 5 were for northern South America and Africa; hence, these regions are explored further. South and East Asia is a region of high population density, highly dependent on agriculture, so this region has also been considered in more detail.

\section{1) Northern SOUth AmericA}

Decreases in precipitation over northern South America under future climate change have been widely reported (Scheff and Frierson 2012; Wang et al. 2020), and linked to changes in the tropical Pacific (Parsons 2020) and the response of vegetation to elevated $\mathrm{CO}_{2}$ (Richardson et al. 2018). Recent declines in dry season precipitation over tropical South America can be attributed to elevated greenhouse gases and land use change (Barkhordarian et al. 2018), while recent increased frequency of dry days over the southern Amazon has been linked to tropical North Atlantic warming and enhanced subsidence of the southern branch of the Hadley cell (Espinoza et al. 2019). Three of the IPCC AR6 regions are considered; South American monsoon (SAM), north South America (NSA), and northeast South America (NES). Figures $6 \mathrm{~b}$ and $6 \mathrm{c}$ shows there is generally good model agreement in the projection of longer dry spells in the dry season across all three regions; for all scenarios the 25th percentile (across the models) is above 0 . Under the high emissions scenarios for CMIP5 and CMIP6 the median increase in the maximum length of dry spells in the dry season ranges between 9 and 26 days, with median increases in the mean length of dry spells in the dry season between 1.4 and 9.4 days. In their analysis of changes in CWD and CDD over Brazil in the CMIP5 models, Avila-Diaz et al. (2020) also found longer dry spells under future climate change, with the largest increases in the northeast. This is a continuation of the recent trend of longer dry spells in northeast Brazil over 1980-2016 (Avila-Diaz et al. 2020).

For the mean and maximum length of wet spells in the wet season the 25th percentile is below 0 for all regions and scenarios indicating strong model agreement on shorter wet spells in the wet season under future climate change (Figs. 6d,e). Under the high emissions scenarios for CMIP5 and CMIP6 median decreases in the maximum length of wet spells in the wet season range between 3 and 13 days, while median decreases in the mean length of wet spells in the wet season range between 0.6 and 3.7 days. It is interesting to note that the largest changes in dry spell lengths are over NES, while the largest changes in wet spell lengths are over NSA; this is consistent with Avila-Diaz et al. (2020), who found the largest decreases in CWD over the central northern part of Brazil.

For both variables and all the regions the changes are larger for the CMIP6 high emissions scenario than the CMIP5 high emissions scenario; this was also noted in the previous section and is thought to be related to the higher climate sensitivity in CMIP6 than in CMIP5 (Meehl et al. 2020).

Time series of mean length of dry spells in the dry season and mean length of wet spells in the wet season for the NES region (Fig. 7) show the same patterns of longer dry spells in the dry season and shorter wet spells in the wet season. The dots at the top of each panel indicate when the range of values in that year is statistically significantly different from the range over 1985-2014 and indicates the emergence of the signal from the noise. This suggests that the increase in the mean length of dry spells in the dry season becomes statistically significantly different between 2020 and 2040 (depending on the emissions scenario) whereas the decrease in the mean length of wet spells in the wet season is not statistically significant until 2060-80 (timings are similar for maximum spell lengths). These times of emergence are indicative, but may not be fully quantified, as we have only used one ensemble member per model. For more robust times of emergence the internal variability should be calculated using a large ensemble. For wet spells in the wet season the change is less significant under the SSP245 scenario and diverges from the SSP585 scenario in the 2060s (Fig. 7b). The apparent jump in dry spell length around 2065 is not a model artifact, but reflects the combination of internal variability and the leveling off of warming in the SSP245 scenario. Figure 7 also shows the large interannual variability in these metrics and the large model spread. Two methodologies were used for calculating the time series; one using varying season start and end dates and one using fixed season start and end dates (see methodology in section 5). The results shown in Fig. 7 were the same for both methodologies, indicating the 

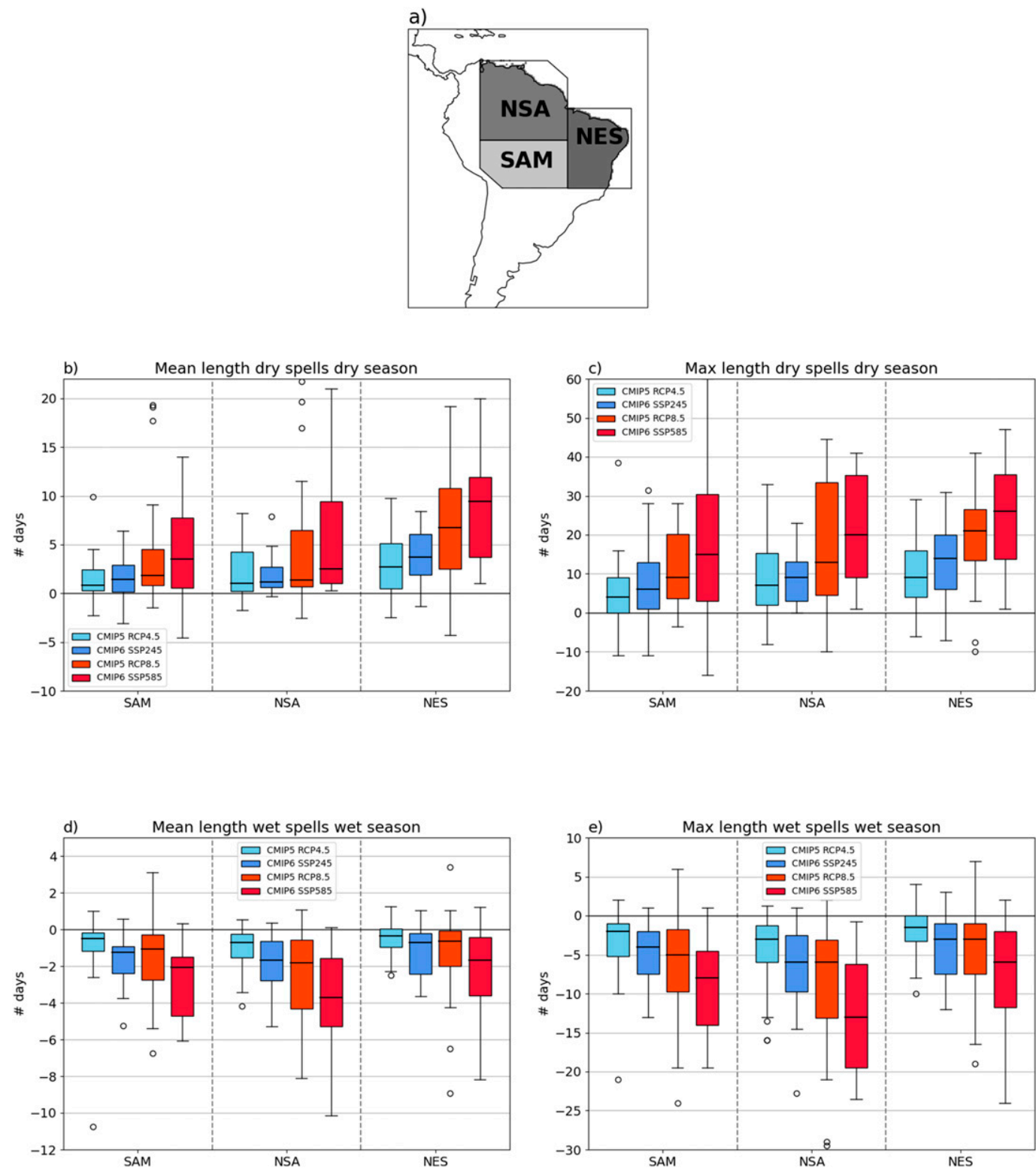

FIG. 6. (a) Region map showing the location of South American monsoon (SAM), north South America (NSA), and northeast South America (NES). (b),(c) Boxplots showing the change in mean/max length of dry spells in the dry season and (d),(e) boxplots showing the change in mean/max length of wet spells in the wet season over SAM, NSA, and NES. The different colors indicate the CMIP era (CMIP5 or CMIP6) and scenario (SSP245, SSP585, RCP4.5, RCP8.5). For all boxplots the change is computed from the historical simulation for 1985-2014 to the select scenario for 2070-99. The box extends from the lower quartile (Q1) to the upper quartile (Q3) of the data and the line in the middle shows the median. The whiskers extend from the first datum greater than Q1 minus 1.5 times the interquartile range to the last datum less than Q3 plus 1.5 times the interquartile range-values outside this range are considered to be outliers and marked with a circle. The same is the case for all boxplots in this paper.

result is robust and insensitive to changing season length. However, for the mean length of dry spells in the wet season and mean length of wet spells in the dry season the signal (increase/decrease, respectively) becomes weaker and less statistically significant when varying onset is used (not shown). This indicates that erroneously including parts of the other season when the time-invariant dates are used can influence the calculation of these metrics, and indicates changes occurring in the margins between the seasons.

\section{2) AFRICA}

Projected changes in the mean length of wet and dry spells are not consistent across the African continent (Figs. 8 and S17). While southwest Africa (SWAF) and southeast Africa 

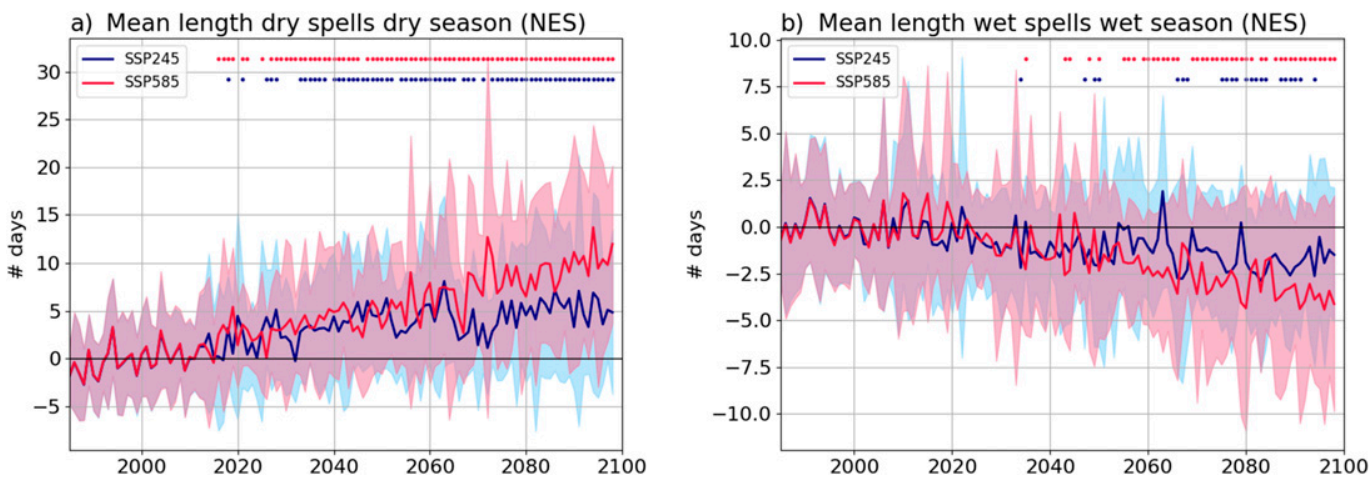

FIG. 7. Time series of (a) mean length of dry spells in the dry season and (b) mean length of wet spells in the wet season for the northeast South America region. The blue (red) line shows the multimodel mean over the CMIP6 models for the SSP245 (SSP585) scenario; the shading indicates one standard deviation. The dots indicate when the range of values from 18 models for that year is significantly different from the range for 1985-2014 at the 5\% level, using a Mann-Whitney $U$ and $t$ test.

(SEAF) show longer dry spells in the dry season (increase in mean and maximum length), with median increases in the maximum length greater than 20 days over SWAF, northeast Africa (NEAF) shows shorter dry spells (median change in the maximum length of dry spells is a decrease of 12 days under CMIP6 SSP585; Figs. 8b,c). There is good model agreement in shorter dry season dry spells over NEAF, with the 25th percentile below 0 for all scenarios. Pinto et al. (2016) also found increases in CDD over southern Africa, with increases of greater than 25 days over Zimbabwe and Botswana, with larger increases under RCP8.5 than under RCP4.5, in agreement with Orlowsky and Seneviratne (2012) and Sillmann et al. (2013b). Over East Africa previous studies report both increases and decreases in dry spell lengths. Over southern Ethiopia, Tegegne et al. (2020) found a decrease in CDD during the 2080s under RCP8.5, in agreement with the findings in Sillmann et al. (2013b). However, Gudoshava et al. (2020) show only small changes (generally less than one day) in CDD in March-May, June-September, and October-December over the Horn of Africa; Ogega et al. (2020) also found no large changes in CDD over Kenya and Uganda. Conversely, Osima et al. (2018) find increasing CDD over the Horn of Africa. Our results here are consistent with the studies of Sillmann et al. (2013b), Orlowsky and Seneviratne (2012) and Tegegne et al. (2020); further detailed studies on this region should explore the range of projections from different studies, taking into account the large variability in model projections over East Africa (Rowell et al. 2015). West Africa (WAF) and Central Africa (CAF) show shorter dry spells in the future (Fig. S17), although the changes are smaller than those over NEAF and model agreement is weaker; Sillmann et al. (2013b) show that changes in CDD are not significant over these regions.

Only two regions show notable changes in the length of wet spells in the wet season; WAF and CAF show median decreases of 3-6 days in the maximum length of wet spells (under high emissions scenarios, Figs. 8d,e). Changes in the mean length also show decreases. While there is generally good model agreement on shorter wet spells in the wet season over WAF and CAF (for the most part the 25 th percentile is below
0 ), there is a large range across the models, particularly under CMIP5 and over CAF. This may be related to poor model representation of the mean climate over this region in CMIP5 models (Creese and Washington 2018) and to the inclusion of a wet-year-round region in equatorial Africa. Klutse et al. (2018) also found a reduction in CWD in June-September over West Africa, with reductions of up to 4 days over Nigeria and Guinea under $2^{\circ} \mathrm{C}$ of global warming. Over Central Africa Mba et al. (2018) found decreases in CWD in both March-May and September-November.

Figure $9 \mathrm{~b}$ shows that the decrease in the length of wet spells in the wet season over WAF becomes statistically significantly different from 1985 to 2014 at around 2050 under SSP585. However, under SSP245 the change does not become consistently statistically significantly different in the period of this time series (up to 2100). For dry spells in the dry season over SEAF the increase in length becomes statistically significantly different from 1985 to 2014 around 2040-60, later than was found for NES (Fig. 9a). For dry spells in the dry season the scenarios diverge in the 2060s, while for wet spells in the wet season the scenarios diverge in the 2040s.

\section{3) ASIA}

Generally, changes in the length of wet and dry spells are smaller and less significant, or exhibit limited model consensus, over Asia. Figure 5 showed significant decreases in the mean length of dry spells in the dry season over northeast China (also found by Han et al. 2018; Dong et al. 2020), but no other significant changes over this region. Figures $10 \mathrm{~b}$ and $10 \mathrm{c}$ confirms that changes in the length of dry spells in the dry season are generally small. The largest change is an increase of four days in the maximum length of dry season dry spells over South Asia (SAS) under CMIP5 RCP8.5; this change is larger in CMIP5 than in CMIP6 (median in CMIP6 SSP585 is an increase of one day), consistent with the slight increase in dry season rainfall over India found in CMIP6 SSP585, but little change in dry season rainfall found in CMIP5 RCP8.5. While there is an increase in the maximum length of dry spells, the change in the mean length of dry spells is small (less than 0.6 days), indicating 

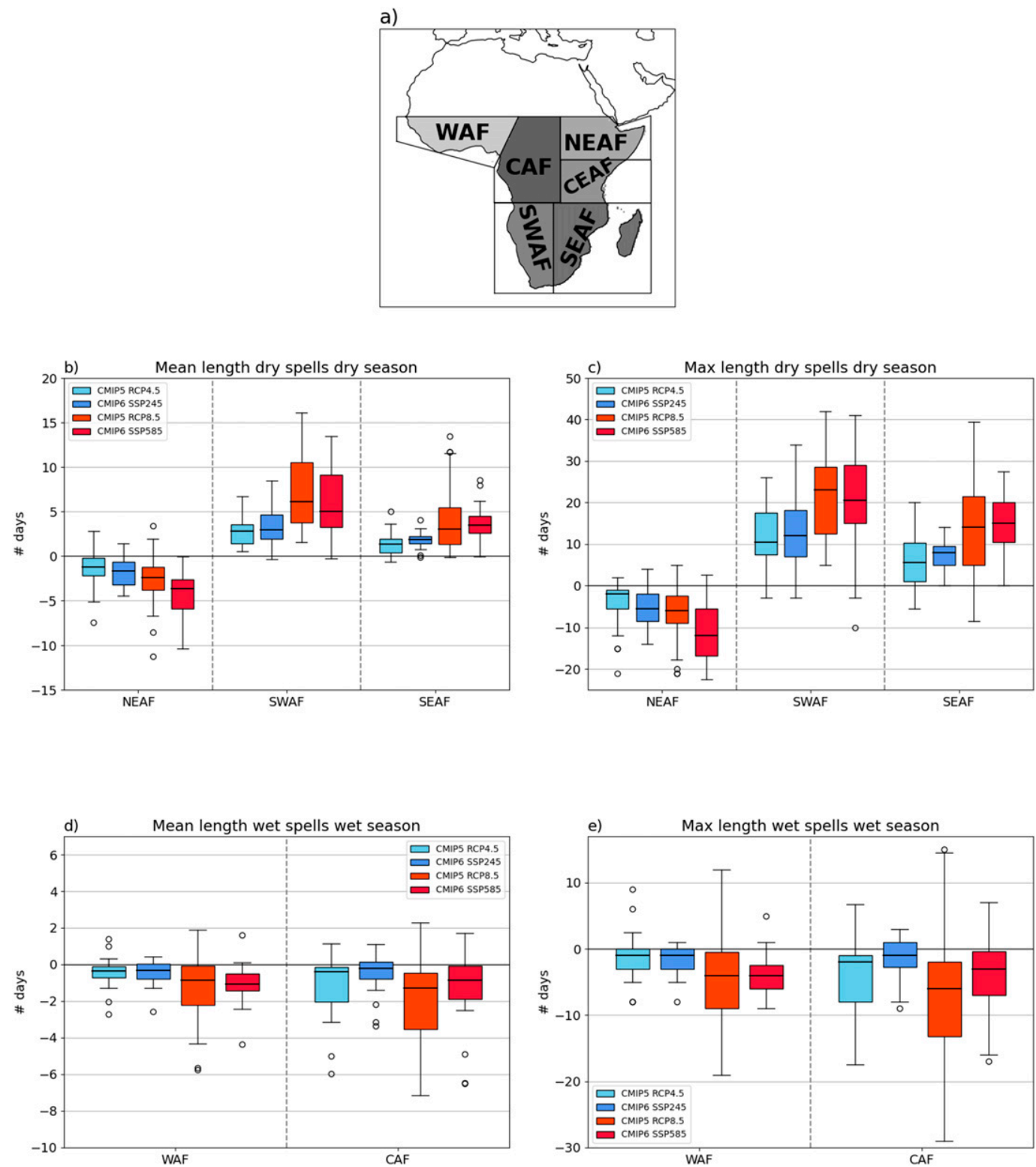

FIG. 8. (a) Region map showing the location of West Africa (WAF), Central Africa (CAF), northeast Africa (NEAF), central East Africa (CEAF), southwest Africa (SWAF), and southeast Africa (SEAF). (b),(c) Boxplots showing the change in mean/max length of dry spells in the dry season over NEAF, SWAF, and SEAF. (d),(e) Boxplots showing mean/max length of wet spells in the wet season over WAF and CAF. The different colors indicate the CMIP era (CMIP5 or CMIP6) and scenario (SSP245, SSP585, RCP4.5, RCP8.5). For all boxplots the change is computed from the historical simulation for 1985-2014 to the select scenario for 2070-99. Results for all regions are shown in Fig. S17.

that for the most part dry season dry spells are not getting longer. An increase in the maximum, but not the mean also suggests an increase in the variability. This highlights the importance of considering the mean as well as the maximum spell length. There is limited model agreement in these changes. Han et al. (2018) also found little change in CDD over South Asia and Southeast Asia in their analysis of CMIP5 models. Aadhar and Mishra (2020) concluded that projections based on CMIP6 multimodel ensembles are not reliable over South Asia as projections are different when the whole ensemble is used compared with just those models that correctly represent current climate. Further work is required to investigate this region in more detail.

Figures $10 \mathrm{~b}$ and $10 \mathrm{c}$ also shows a slight increase in the maximum length of dry season dry spells over Southeast Asia (SEA). It should be noted that much of this region experiences a wet-year-round rainfall regime, therefore, only a small region (over Myanmar and Thailand) will be contributing to this signal; 

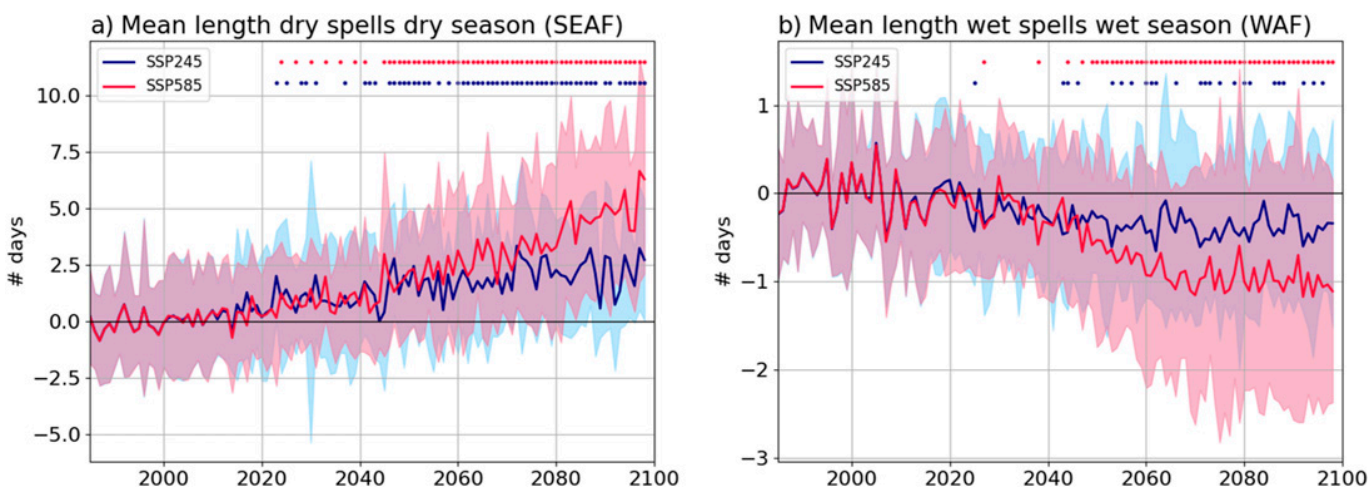

FIG. 9. Time series of (a) mean length of dry spells in the dry season over southeast Africa (SEAF) and (b) mean length of wet spells in the wet season over West Africa (WAF). The blue/red line shows the multimodel mean over the CMIP6 models for the SSP245/SSP585 scenario; the shading indicates one standard deviation. The dots indicate when the range of values from 18 models for that year is significantly different from the range for 1985-2014 at the $5 \%$ level, using a Mann-Whitney $U$ and $t$ test.

this is supported by the findings of Ge et al. (2019), who show the largest increases in CDD in the SEA region are over the Myanmar-Thailand peninsula. Figures 10b and 10c shows the median changes are small ( 2 and 3 days), and again, only seen in the maximum not the mean, with limited model agreement.

Figures 10d and 10e shows changes in the length of wet spells in the wet season, with median decreases in the maximum length of 2 and 4 days over SEA and little change in other regions. This is consistent with a decrease in the number of wet season rainy days over this region. Again, the change in the mean is small (less than 0.4 days), indicating only the longest wet spells are getting shorter, not all wet spells, and also indicating a change in the variability. While Ge et al. (2019) show increases in CWD in the CORDEX models over SEA, they also find that the increase is larger under $1.5^{\circ} \mathrm{C}$ of global warming than under $2^{\circ} \mathrm{C}$ of global warming, and under $2^{\circ} \mathrm{C}$ of global warming some regions show decreases (e.g., Borneo). Global warming of $2^{\circ} \mathrm{C}$ is reached at around 2040 under SSP585 (O'Neill et al. 2016); therefore, if the increased warming continues to decrease the change in CWD, this is consistent with our finding of shorter wet spells. Over East Asia (EAS) the changes are small, consistent with the results in Fig. 5.

\section{e. Seasonal maximum temperature}

Interpreting agricultural implications of precipitation changes cannot be considered in isolation from temperature, as the aridity or dryness over a region is determined by the difference between supply (precipitation) and demand [measured by potential evapotranspiration (PET)] (Dai et al. 2018). Elevated greenhouse gas levels lead to increasing temperatures, which combined with small changes in relative humidity, lead to large increases in the vapor pressure deficit and widespread increases in PET (Dai et al. 2018). Zhao and Dai (2015) found that rising temperatures and vapor deficits explain most of the projected ubiquitous global PET increase. On the other hand, elevated $\mathrm{CO}_{2}$ concentrations modify how vegetation responds to changing water availability through a complex and uncertain combination of increased plant growth and increased water use efficiency (Mankin et al. 2019; Peters et al. 2018;
Kooperman et al. 2018). Furthermore, rainfall changes exert a substantial influence on temperature changes since less cloud and rainfall increases absorbed solar radiation while drier soils increase the sensible heat fraction. Therefore, temperature responses in wet and dry seasons are not expected to be uniform and are thus of considerable additional interest.

Figure 11 shows increasing temperatures across the tropics in both wet and dry seasons, as projected under future climate change. Over northern South America, southern Africa, and parts of Asia, the increase in dry season maximum temperature is up to $3^{\circ} \mathrm{C}$ greater than the increase in wet season maximum temperature (Figs. 11a,b); Zhou et al. (2015) also found the largest temperature increases over drier regions. In both northern South America and southern Africa this increase in dry season maximum temperature is combined with a decrease in dry season rainfall (Fig. 4b), which may lead to a substantial drying of soils during the dry season, affecting perennial crops. Dai et al. (2018) found large increases in PET and decreases in soil moisture over northern South America and southern Africa. Decreases in soil moisture across northern South America and southern Africa were also reported by Collins et al. (2013) and Zhao and Dai (2015). Furthermore, Zhao and Dai (2015) found decreases in soil moisture (hence increased surface drying) in regions projected to receive higher precipitation amounts, due to fewer wet days and longer dry spells and high temperatures, highlighting the importance of changes in frequency in precipitation, in addition to changes in amount.

The contours on Fig. 11 indicate that under the historical simulation over 1985-2014 only northern Australia and the Sahel have mean seasonal maximum temperatures greater than $35^{\circ} \mathrm{C}$ (dashed contour), whereas by the end of the twentyfirst century under SSP585 parts of India, the Sahel, northern South America, and parts of northern Australia may all experience mean dry season maximum temperatures of greater than $35^{\circ} \mathrm{C}$ (solid contour). This may have negative impacts on crops including sorghum (FAO 2020). However, during the wet season temperatures are generally less than $35^{\circ} \mathrm{C}$, except over northern Australia and parts of the Sahel. This may mean 

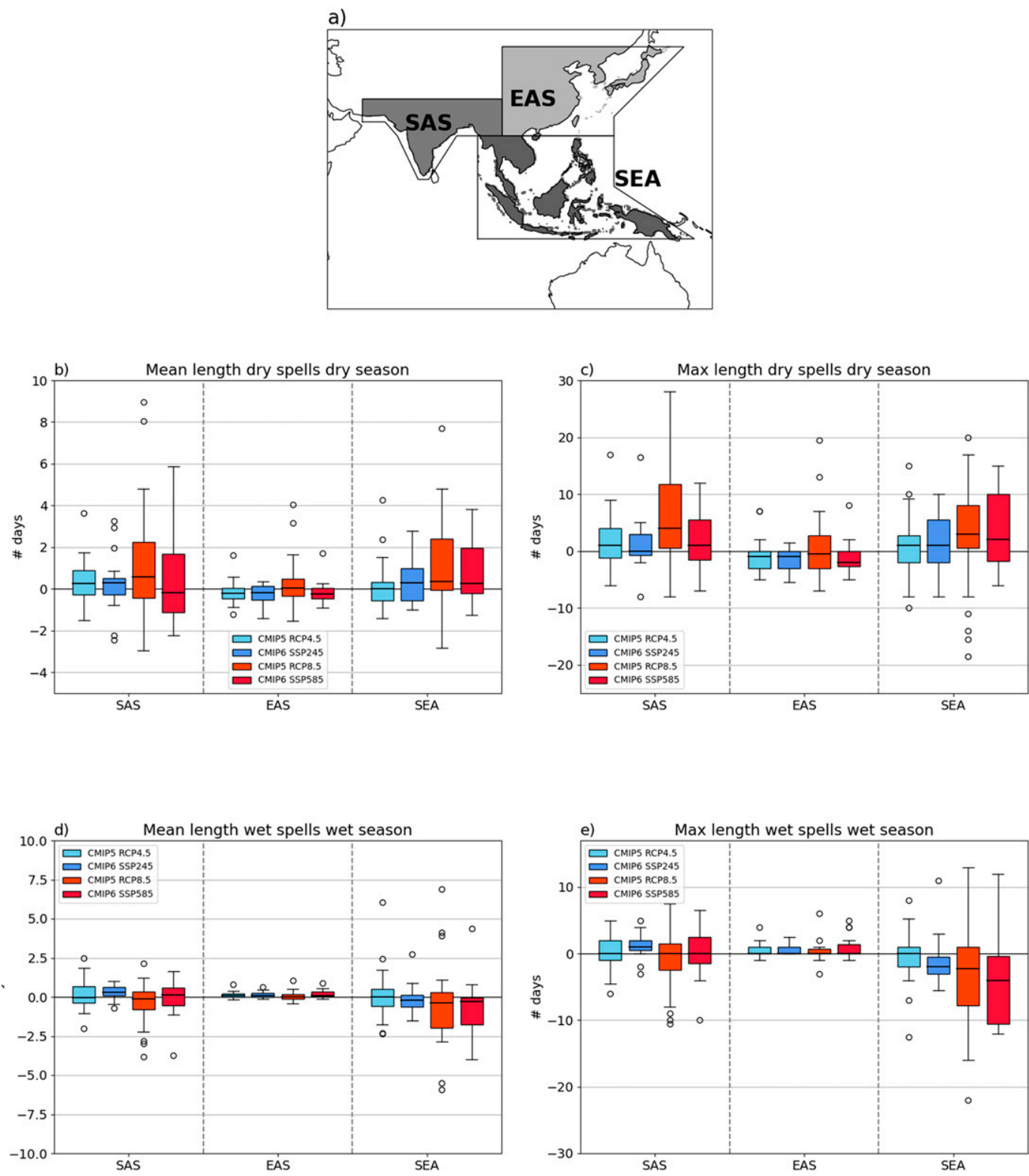

FIG. 10. (a) Region map showing the location of South Asia (SAS), East Asia (EAS), and Southeast Asia (SEA). (b),(c) Boxplots showing the change in mean/max length of dry spells in the dry season. (d),(e) Boxplots showing the change in mean/max length of wet spells in the wet season. The different colors indicate the CMIP era (CMIP5 or CMIP6) and scenario (SSP245, SSP585, RCP4.5, RCP8.5). For all boxplots the change is computed from the historical simulation for 1985-2014 to the select scenario for 2070-99.

that crops grown during the wet season are less impacted by these elevated temperatures.

\section{Conclusions}

Changes in the mean and maximum lengths of wet and dry spells (and mean maximum temperature) have been calculated separately for the climatological wet and dry seasons using an ensemble of CMIP5 and CMIP6 models across the global tropics and subtropics. An objective methodology is used to classify the seasonality at each location and to determine the timing of the climatological wet and dry season(s); metrics including total seasonal rainfall, number of rainy days, rain per rainy day, and the mean and maximum length of wet and dry spells are then calculated for the wet and dry seasons separately.

Our main results are as follows (also summarized in Fig. 12):

- Onset of the annual wet season is projected to get later across South America, southern Africa, West Africa, and the Sahel, with changes of up to 2 weeks. Over East Asia the onset is projected to be earlier. Cessation of the annual wet season is 


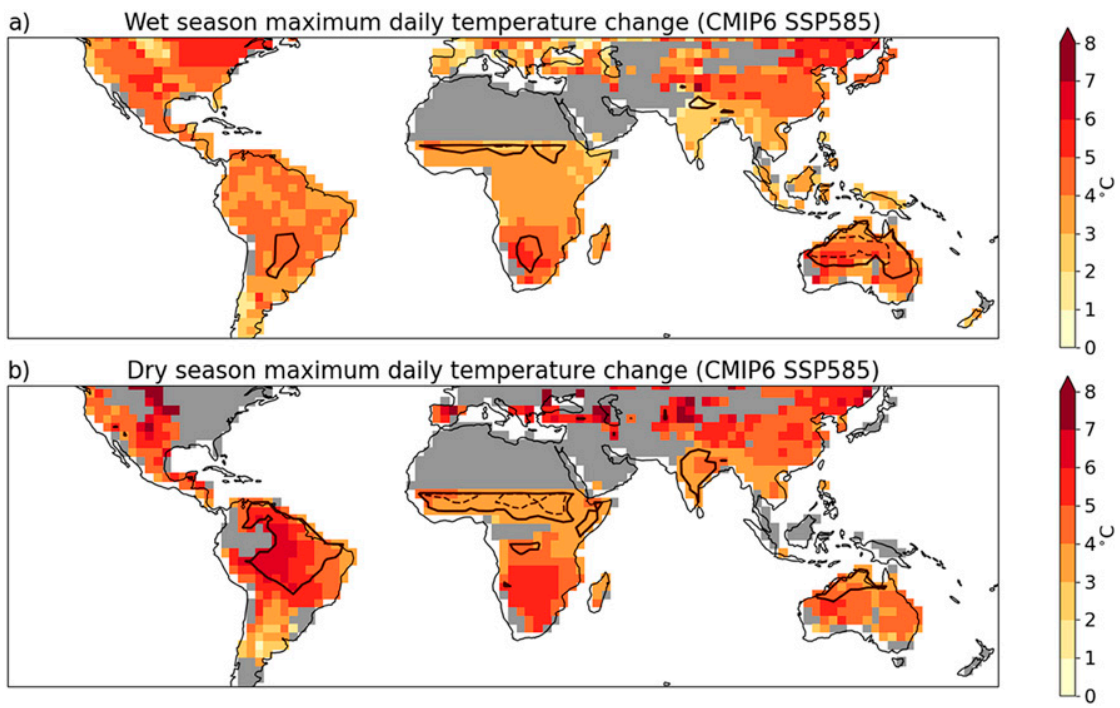

FIG. 11. CMIP6 multimodel median change in (a) mean wet season maximum daily temperature and (b) mean dry season maximum daily temperature for the SSP585 scenario over 2070-99 compared with the historical simulation over 1985-2014. The contours indicate where the CMIP6 multimodel median wet and dry season mean daily maximum temperature is greater than $35^{\circ} \mathrm{C}$ for the historical simulation over 1985-2014 (dashed line) and the SSP585 simulation over 2070-99 (solid line). In all panels gray regions indicate where at least $50 \%$ of the models do not give a value (dry year-round or wet year-round in the dry season plots).

projected to be later over the Sahel, parts of Asia, and Central America. These changes are consistent with the projected global phase delay of the seasonal cycle of precipitation under future climate change (Dwyer et al. 2014; Song et al. 2018).

- Changes in the mean and maximum length of dry spells are largest during the dry season. Increasing dry season dry spell lengths were found over central America, northeast South America, southern Africa, and Australia. Shorter dry spells in the dry season are found over East Africa and parts of the Sahel and East Asia. Changes in the length of dry spells in the wet season are generally small, with only the Mediterranean and southern Europe showing significant increases.

- Statistically significant decreases in the length of wet spells in the wet season are found over central and northern South America and West/Central Africa.

- For the most part, changes were of the same sign in CMIP5 and CMIP6, but of larger magnitude under CMIP6, possibly related to the higher climatic sensitivity (Meehl et al. 2020).

- The time at which the change becomes statistically significantly different from the historical period varies with metric and region; while the increase in length of dry spells in the dry season over northeast South America is statistically significant around 2020-40, the decrease in the length of wet spells in the wet season over West Africa is not statistically significant until around 2050. Times of emergence here are indicative; more robust times of emergence could be calculated using a larger ensemble.

- Mean maximum temperature increases are greater for the dry season than for the wet season, with mean maximum dry season temperatures increasing by up to $7^{\circ} \mathrm{C}$, particularly over South America, southern Africa, and parts of Asia.
While only northern Australia is projected to have large areas with mean maximum wet season temperatures $>35^{\circ} \mathrm{C}$ at the end of the twenty-first century under SSP585, northern South America, the Sahel, and India are projected to have mean maximum dry season temperatures $>35^{\circ} \mathrm{C}$ at the end of the twenty-first century under SSP585.

This paper aimed to address the question "Do changes in the length of wet and dry spells differ in climatologically wet and dry seasons?" Here it has been decisively shown, considering both the mean and maximum wet/dry spell lengths (thus considering all wet/dry spells, not just the longest) that changes in the length of wet and dry spells are different in wet and dry seasons, and that the increases in dry spell lengths expected under future climate change mostly occur during the annual dry seasons. This has important implications for agriculture across the tropics, and suggests that crops grown solely during the wet season may be less affected by longer dry spells and increased water stress. However, for crops grown during the dry season and perennial crops, longer dry spells in the dry season, combined with lower dry season rainfall and fewer dry season rainy days may lead to elevated dry season water stress. This elevated dry season water stress will be further exacerbated by increased evaporative demand due to higher temperatures; Scheff and Frierson (2015) found aridification generally dominates over humidification in the tropics and subtropics due to temperature-driven increases in potential evapotranspiration. Regions such as central America, northeast South America, southern Africa, and Australia will be most impacted by this. Further work, using detailed crop models, is required to determine the impacts on individual crops. 


\section{DRY SEASON}
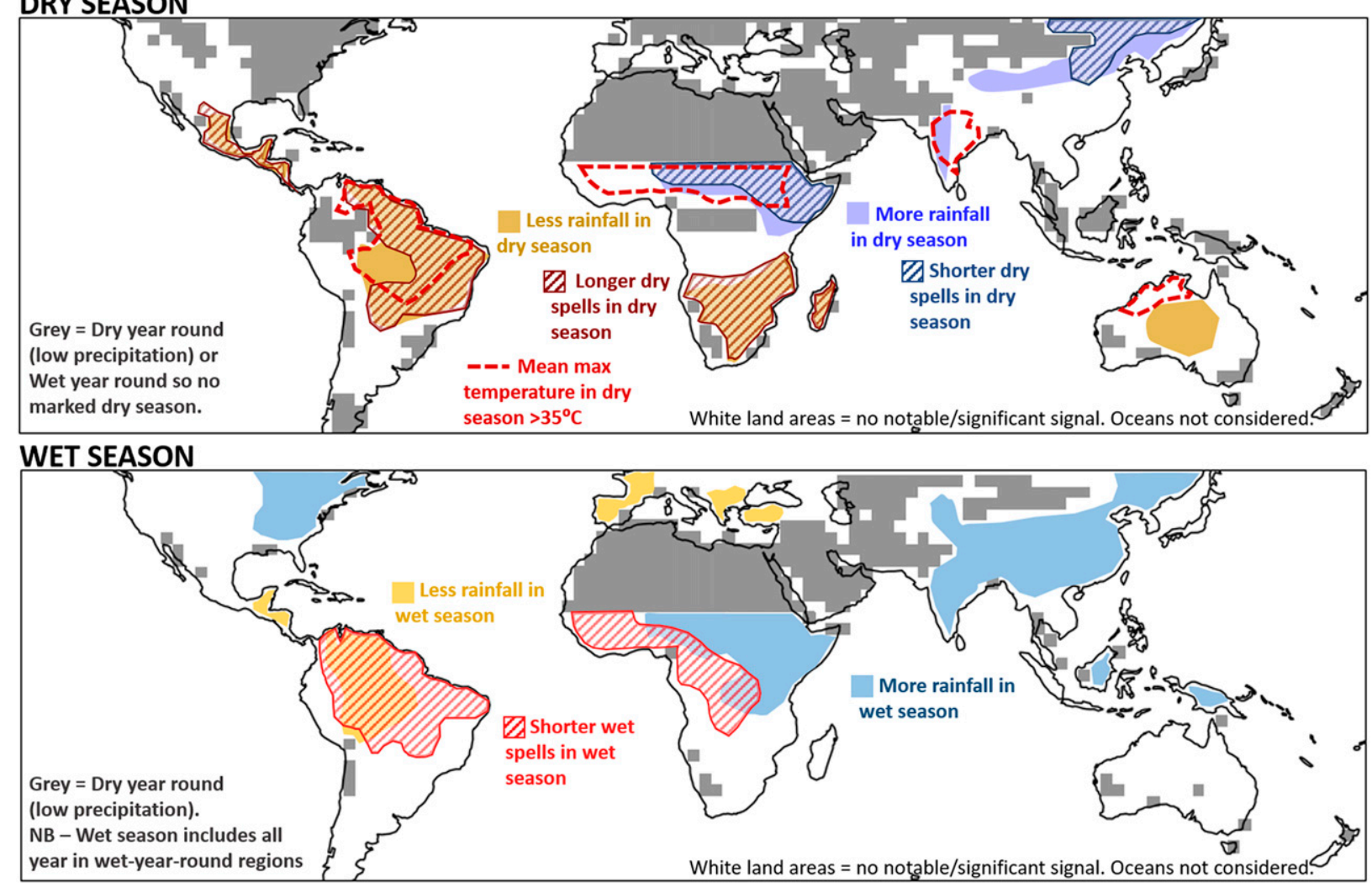

FIG. 12. Schematic summarizing the changes in wet/dry season rainfall and wet/dry spell lengths in wet/dry seasons found here; the top panel is for dry seasons and the bottom row is for wet seasons (including regions that are wet year-round). (top) Longer dry spells and lower rainfall during the dry season are found over Central and South America and southern Africa. Shorter dry spells and more rainfall during the dry season are found over East Africa and parts of Asia and the Sahel. (bottom) More rainfall in the wet season is found over East Africa and Asia. Less rainfall in the wet season is found over northern South America. Reductions in the length of wet spells in the wet season are found over South America and West and Central Africa.

Regional variations in the response of wet and dry spells to elevated greenhouse gas concentrations have been identified; the aim of this paper is to assess the changes in wet/dry season precipitation characteristics and not to understand the regional changes in terms of circulation change. Regional changes in rainfall across the tropics are driven by a range of factors including changes in the intertropical convergence zone (contraction, intensification, and timing; Dwyer et al. 2014; Su et al. 2017; Song et al. 2018) and subtropical drying, which is determined by complex interplay between Hadley Cell expansion (Seidel et al. 2008; Scheff and Frierson 2012), land ocean warming contrasts (Karnauskas and Ummenhofer 2014; He and Soden 2017), and vegetation responses to elevated $\mathrm{CO}_{2}$ (Mankin et al. 2018). Further work is required to understand the changing regional/local circulations and energy and water fluxes that lead to these changes over different regions.

Acknowledgments. We thank Salvatore Pascale and two anonymous reviewers for their insightful and constructive reviews. We acknowledge the World Climate Research Programme, which, through its Working Group on Coupled Modelling, coordinated and promoted CMIP6. We thank the climate modeling groups (Tables S1 and S2) for producing and making available their model output, the Earth System Grid Federation (ESGF) for archiving the data and providing access, and the multiple funding agencies who support CMIP6 and ESGF. For CMIP5 the U.S. Department of Energy's Program for Climate Model Diagnosis and Intercomparison provides coordinating support and led development of software infrastructure in partnership with the Global Organization for Earth System Science Portals. Emily Black was supported by the National Centre for Atmospheric Science via the NERC/GCRF programme Atmospheric hazard in developing countries: risk assessment and early warning (ACREW). Emily Black also gratefully acknowledges support from the Global Challenges Research Fund project, SatWIN-ALERT(NE/R014116/1). Richard P. Allan was funded by the National Centre for Earth Observation Grant NE/RO16518/1. We are grateful to the Mars Wrigley Confectionery research team for stimulating discussions on the wider context and applications of this work.

Data availability statement. CHIRPS rainfall data are available from https://data.chc.ucsb.edu/products/CHIRPS-2.0/. CMIP5 and CMIP6 data were obtained from the British Atmospheric 
Data Centre (BADC) hosted at the Centre for Environmental Data Analysis (CEDA).

\section{REFERENCES}

Aadhar, S., and V. Mishra, 2020: On the projected decline in droughts over South Asia in CMIP6 multimodel ensemble. J. Geophys. Res. Atmos., 125, e2020JD033587, https://doi.org/ 10.1029/2020JD033587.

Allan, R. P., and Coauthors, 2020: Advances in understanding large-scale responses of the water cycle to climate change. Ann. N. Y. Acad. Sci., 1472, 49-75, https://doi.org/10.1111/ nyas.14337.

Allen, M. R., and W. J. Ingram, 2002: Constraints on future changes in climate and the hydrologic cycle. Nature, 419, 228-232, https://doi.org/10.1038/nature01092.

Avila-Diaz, A., V. Benezoli, F. Justino, R. Torres, and A. Wilson, 2020: Assessing current and future trends of climate extremes across Brazil based on reanalyses and Earth system model projections. Climate Dyn., 55, 1403-1426, https://doi.org/ 10.1007/s00382-020-05333-z.

Barkhordarian, A., H. von Storch, A. Behrangi, P. C. Loikith, C. R. Mechoso, and J. Detzer, 2018: Simultaneous regional detection of land-use changes and elevated GHG levels: The case of spring precipitation in tropical South America. Geophys. Res. Lett., 45, 6262-6271, https://doi.org/10.1029/2018GL078041.

Beck, H. E., E. F. Wood, M. Pan, C. K. Fisher, D. G. Miralles, A. I. J. M. van Dijk, T. R. McVicar, and R. F. Adler, 2019: MSWEP V2 global 3-hourly $0.1^{\circ}$ precipitation: Methodology and quantitative assessment. Bull. Amer. Meteor. Soc., 100, 473-500, https://doi.org/10.1175/BAMS-D-17-0138.1.

Biasutti, M., and A. H. Sobel, 2009: Delayed Sahel rainfall and global seasonal cycle in a warmer climate. Geophys. Res. Lett., 36, L23707, https://doi.org/10.1029/2009GL041303.

Brogli, R., S. L. Sørland, N. Kröner, and C. Schär, 2019: Causes of future Mediterranean precipitation decline depend on the season. Environ. Res. Lett., 14, 114017, https://doi.org/10.1088/ 1748-9326/ab4438.

Chou, C., J. C. H. Chiang, C.-W. Lan, C.-H. Chung, Y.-C. Liao, and C.-J. Lee, 2013: Increase in the range between wet and dry season precipitation. Nat. Geosci., 6, 263-267, https://doi.org/ 10.1038/ngeo1744.

Collins, M., and Coauthors, 2013: Long-term climate change: Projections, commitments and irreversibility. Climate Change 2013: The Physical Science Basis, T. F. Stocker et al., Eds., Cambridge University Press, 1029-1136.

Correa, I. C., P. A. Arias, and M. Rojas, 2020: Evaluation of multiple indices of the South American monsoon. Int. J. Climatol., 41, E2801-E2819, https://doi.org/10.1002/joc.6880.

Creese, A., and R. Washington, 2018: A process-based assessment of CMIP5 rainfall in the Congo Basin: The September-November rainy season. J. Climate, 31, 7417-7439, https://doi.org/10.1175/ JCLI-D-17-0818.1.

Dai, A., T. Zhao, and J. Chen, 2018: Climate change and drought: A precipitation and evaporation perspective. Curr. Climate Change Rep., 4, 301-312, https://doi.org/10.1007/s40641-0180101-6.

Deng, S., C. Sheng, N. Yang, L. Song, and Q. Huang, 2020: Anthropogenic forcing enhances rainfall seasonality in global land monsoon regions. Environ. Res. Lett., 15, 104057, https:// doi.org/10.1088/1748-9326/abafd3.

Dong, G., Z. Jiang, Z. Tian, E. Buonomo, L. Sun, and D. Fan, 2020: Projecting changes in mean and extreme precipitation over eastern China during 2041-2060. Earth Space Sci., 7, e2019EA001024, https://doi.org/10.1029/2019EA001024.

Dunning, C. M., E. C. Black, and R. P. Allan, 2016: The onset and cessation of seasonal rainfall over Africa. J. Geophys. Res. Atmos., 121, 11405-11424, https://doi.org/10.1002/ 2016JD025428.

- R. P. Allan, and E. Black, 2017: Identification of deficiencies in seasonal rainfall simulated by CMIP5 climate models. Environ. Res. Lett., 12, 114001, https://doi.org/10.1088/ 1748-9326/aa869e.

_ E. E. Black, and R. P. Allan, 2018: Later wet seasons with more intense rainfall over Africa under future climate change. J. Climate, 31, 9719-9738, https://doi.org/10.1175/JCLI-D-180102.1.

Dwyer, J. G., M. Biasutti, and A. H. Sobel, 2014: The effect of greenhouse gas-induced changes in SST on the annual cycle of zonal mean tropical precipitation. J. Climate, 27, 4544-4565, https://doi.org/10.1175/JCLI-D-13-00216.1.

Eekhout, J. P. C., J. E. Hunink, W. Terink, and J. de Vente, 2018: Why increased extreme precipitation under climate change negatively affects water security. Hydrol. Earth Syst. Sci., 22, 5935-5946, https://doi.org/10.5194/hess-22-5935-2018.

Espinoza, J. C., J. Ronchail, J. A. Marengo, and H. Segura, 2019: Contrasting North-South changes in Amazon wet-day and dry-day frequency and related atmospheric features (19812017). Climate Dyn., 52, 5413-5430, https://doi.org/10.1007/ s00382-018-4462-2.

Eyring, V., S. Bony, G. A. Meehl, C. A. Senior, B. Stevens, R. J. Stouffer, and K. E. Taylor, 2016: Overview of the Coupled Model Intercomparison Project Phase 6 (CMIP6) experimental design and organization. Geosci. Model Dev., 9, 1937-1958, https://doi.org/10.5194/gmd-9-1937-2016.

FAO, 2020: Crop information: Sorghum. Accessed 1 December 2020, http://www.fao.org/land-water/databases-and-software/ crop-information/sorghum/en/.

Feng, X., A. Porporato, and I. Rodriguez-Iturbe, 2013: Changes in rainfall seasonality in the tropics. Nat. Climate Change, $\mathbf{3}$, 811-815, https://doi.org/10.1038/nclimate1907.

Funk, C., and Coauthors, 2015: The climate hazards infrared precipitation with stations - a new environmental record for monitoring extremes. Sci. Data, 2, 150066, https://doi.org/ 10.1038/sdata.2015.66.

—, L. Harrison, L. Alexander, P. Peterson, A. Behrangi, and G. Husak, 2019: Exploring trends in wet-season precipitation and drought indices in wet, humid and dry regions. Environ. Res. Lett., 14, 115002, https://doi.org/10.1088/ 1748-9326/ab4a6c.

Ge, F., and Coauthors, 2019: Risks of precipitation extremes over Southeast Asia: does $1.5^{\circ} \mathrm{C}$ or $2^{\circ} \mathrm{C}$ global warming make a difference? Environ. Res. Lett., 14, 044015, https://doi.org/ 10.1088/1748-9326/aaff7e/meta.

Giorgi, F., E.-S. Im, E. Coppola, N. Diffenbaugh, X. Gao, L. Mariotti, and Y. Shi, 2011: Higher hydroclimatic intensity with global warming. J. Climate, 24, 5309-5324, https://doi.org/ 10.1175/2011JCLI3979.1.

, E. Coppola, and F. Raffaele, 2014: A consistent picture of the hydroclimatic response to global warming from multiple indices: Models and observations. J. Geophys. Res. Atmos., 119, 11 695-11 708, https://doi.org/10.1002/2014JD022238.

— , F. Raffaele, and E. Coppola, 2019: The response of precipitation characteristics to global warming from climate projections. Earth Syst. Dyn., 10, 73-89, https://doi.org/10.5194/ esd-10-73-2019. 
Gudoshava, M., and Coauthors, 2020: Projected effects of $1.5^{\circ} \mathrm{C}$ and $2^{\circ} \mathrm{C}$ global warming levels on the intra-seasonal rainfall characteristics over the Greater Horn of Africa. Environ. Res. Lett., 15, 034037, https://doi.org/10.1088/1748-9326/ab6b33.

Ha, K.-J., S. Moon, A. Timmermann, and D. Kim, 2020: Future changes of summer monsoon characteristics and evaporative demand over Asia in CMIP6 simulations. Geophys. Res. Lett., 47, e2020GL087492, https://doi.org/10.1029/2020GL087492.

Han, T., H. Chen, X. Hao, and H. Wang, 2018: Projected changes in temperature and precipitation extremes over the Silk Road Economic Belt regions by the Coupled Model Intercomparison Project Phase 5 multi-model ensembles. Int. J. Climatol., 38, 4077-4091, https://doi.org/10.1002/joc.5553.

He, C., T. Li, and W. Zhou, 2020: Drier North American monsoon in contrast to Asian-African monsoon under global warming. J. Climate, 33, 9801-9816, https://doi.org/10.1175/JCLI-D-200189.1.

He, J., and B. J. Soden, 2017: A re-examination of the projected subtropical precipitation decline. Nat. Climate Change, 7, 5357, https://doi.org/10.1038/nclimate3157.

Held, I. M., and B. J. Soden, 2006: Robust responses of the hydrological cycle to global warming. J. Climate, 19, 5686-5699, https://doi.org/10.1175/JCLI3990.1.

Herrmann, S. M., and K. I. Mohr, 2011: A continental-scale classification of rainfall seasonality regimes in Africa based on gridded precipitation and land surface temperature products. J. Appl. Meteor. Climatol., 50, 2504-2513, https://doi.org/10.1175/ JAMC-D-11-024.1.

Iturbide, M., and Coauthors, 2020: An update of IPCC climate reference regions for subcontinental analysis of climate model data: Definition and aggregated datasets. Earth Syst. Sci. Data, 12, 2959-2970, https://doi.org/10.5194/essd-12-2959-2020.

Karnauskas, K. B., and C. C. Ummenhofer, 2014: On the dynamics of the Hadley circulation and subtropical drying. Climate Dyn., 42, 2259-2269, https://doi.org/10.1007/s00382-014-2129-1.

Kitoh, A., H. Endo, K. Krishna Kumar, I. F. Cavalcanti, P. Goswami, and T. Zhou, 2013: Monsoons in a changing world: A regional perspective in a global context. J. Geophys. Res., 118, 30533065, https://doi.org/10.1002/jgrd.50258.

Klutse, N. A. B., and Coauthors, 2018: Potential impact of $1.5^{\circ} \mathrm{C}$ and $2^{\circ} \mathrm{C}$ global warming on consecutive dry and wet days over West Africa. Environ. Res. Lett., 13, 055013, https://doi.org/ 10.1088/1748-9326/aab37b.

Kooperman, G. J., M. D. Fowler, F. M. Hoffman, C. D. Koven, K. Lindsay, M. S. Pritchard, A. L. Swann, and J. T. Randerson, 2018: Plant physiological responses to rising $\mathrm{CO}_{2}$ modify simulated daily runoff intensity with implications for globalscale flood risk assessment. Geophys. Res. Lett., 45, $12457-$ 12 466, https://doi.org/10.1029/2018GL079901.

Kumar, S., R. P. Allan, F. Zwiers, D. M. Lawrence, and P. A. Dirmeyer, 2015: Revisiting trends in wetness and dryness in the presence of internal climate variability and water limitations over land. Geophys. Res. Lett., 42, 10 867-10 875, https:// doi.org/10.1002/2015GL066858.

Lan, C.-W., M.-H. Lo, C.-A. Chen, and J.-Y. Yu, 2019: The mechanisms behind changes in the seasonality of global precipitation found in reanalysis products and CMIP5 simulations. Climate Dyn., 53, 4173-4187, https://doi.org/10.1007/ s00382-019-04781-6.

Lau, W. K.-M., H.-T. Wu, and K.-M. Kim, 2013: A canonical response of precipitation characteristics to global warming from CMIP5 models. Geophys. Res. Lett., 40, 3163-3169, https:// doi.org/10.1002/grl.50420.
Liebmann, B., I. Bladé, G. N. Kiladis, L. M. Carvalho, G. B. Senay, D. Allured, S. Leroux, and C. Funk, 2012: Seasonality of African precipitation from 1996 to 2009. J. Climate, 25, 43044322, https://doi.org/10.1175/JCLI-D-11-00157.1.

Mankin, J. S., R. Seager, J. E. Smerdon, B. I. Cook, A. P. Williams, and R. M. Horton, 2018: Blue water trade-offs with vegetation in a $\mathrm{CO}_{2}$-enriched climate. Geophys. Res. Lett., 45, 3115-3125, https://doi.org/10.1002/2018GL077051.

$-, \ldots, \ldots, \ldots$, and,- 2019 : Mid-latitude freshwater availability reduced by projected vegetation responses to climate change. Nat. Geosci., 12, 983-988, https://doi.org/10.1038/ s41561-019-0480-x.

Marvel, K., M. Biasutti, C. Bonfils, K. E. Taylor, Y. Kushnir, and B. I. Cook, 2017: Observed and projected changes to the precipitation annual cycle. J. Climate, 30, 4983-4995, https:// doi.org/10.1175/JCLI-D-16-0572.1.

Mba, W. P., and Coauthors, 2018: Consequences of $1.5^{\circ} \mathrm{C}$ and $2^{\circ} \mathrm{C}$ global warming levels for temperature and precipitation changes over Central Africa. Environ. Res. Lett., 13, 055011, https://doi.org/10.1088/1748-9326/aab048.

Meehl, G. A., C. A. Senior, V. Eyring, G. Flato, J.-F. Lamarque, R. J. Stouffer, K. E. Taylor, and M. Schlund, 2020: Context for interpreting equilibrium climate sensitivity and transient climate response from the CMIP6 Earth system models. Sci. $A d v .$, 6, eaba1981, https://doi.org/10.1126/sciadv.aba1981.

Ogega, O. M., J. Koske, J. B. Kung'u, E. Scoccimarro, H. S. Endris, and M. N. Mistry, 2020: Heavy precipitation events over East Africa in a changing climate: Results from CORDEX RCMs. Climate Dyn., 55, 993-1009, https://doi.org/10.1007/s00382020-05309-z.

O'Neill, B. C., and Coauthors, 2016: The scenario model intercomparison project (ScenarioMIP) for CMIP6. Geosci. Model Dev., 9, 3461-3482, https://doi.org/10.5194/gmd-9-3461-2016.

Orlowsky, B., and S. I. Seneviratne, 2012: Global changes in extreme events: Regional and seasonal dimension. Climatic Change, 110, 669-696, https://doi.org/10.1007/s10584-0110122-9.

Osima, S., and Coauthors, 2018: Projected climate over the Greater Horn of Africa under $1.5^{\circ} \mathrm{C}$ and $2^{\circ} \mathrm{C}$ global warming. Environ. Res. Lett., 13, 065004, https://doi.org/10.1088/1748-9326/aaba1b.

Parsons, L., 2020: Implications of CMIP6 projected drying trends for 21st century Amazonian drought risk. Earth's Future, 8, e2020EF001608, https://doi.org/10.1029/2020EF001608.

Pascale, S., V. Lucarini, X. Feng, A. Porporato, and S. ul Hasson, 2016: Projected changes of rainfall seasonality and dry spells in a high greenhouse gas emissions scenario. Climate Dyn., 46, 1331-1350, https://doi.org/10.1007/s00382-015-2648-4.

Peters, W., and Coauthors, 2018: Increased water-use efficiency and reduced $\mathrm{CO}_{2}$ uptake by plants during droughts at a continental scale. Nat. Geosci., 11, 744-748, https://doi.org/10.1038/ s41561-018-0212-7.

Pinto, I., C. Lennard, M. Tadross, B. Hewitson, A. Dosio, G. Nikulin, H.-J. Panitz, and M. E. Shongwe, 2016: Evaluation and projections of extreme precipitation over southern Africa from two CORDEX models. Climatic Change, 135, 655-668, https://doi.org/10.1007/s10584-015-1573-1.

Polade, S. D., D. W. Pierce, D. R. Cayan, A. Gershunov, and M. D. Dettinger, 2014: The key role of dry days in changing regional climate and precipitation regimes. Sci. Rep., 4, 4364, https:// doi.org/10.1038/srep04364.

Polson, D., and G. Hegerl, 2017: Strengthening contrast between precipitation in tropical wet and dry regions. Geophys. Res. Lett., 44, 365-373, https://doi.org/10.1002/2016GL071194. 
Richardson, T., and Coauthors, 2018: Carbon dioxide physiological forcing dominates projected eastern Amazonian drying. Geophys. Res. Lett., 45, 2815-2825, https://doi.org/10.1002/ 2017GL076520.

Rockström, J., and Coauthors, 2010: Managing water in rainfed agriculture-The need for a paradigm shift. Agric. Water Manage., 97, 543-550, https://doi.org/10.1016/j.agwat.2009.09.009.

Rowell, D. P., B. B. Booth, S. E. Nicholson, and P. Good, 2015: Reconciling past and future rainfall trends over East Africa. J. Climate, 28, 9768-9788, https://doi.org/10.1175/JCLI-D-150140.1 .

Scheff, J., and D. M. Frierson, 2012: Robust future precipitation declines in CMIP5 largely reflect the poleward expansion of model subtropical dry zones. Geophys. Res. Lett., 39, L18704, https://doi.org/10.1029/2012GL052910.

$\longrightarrow$, and —, 2015: Terrestrial aridity and its response to greenhouse warming across CMIP5 climate models. J. Climate, $\mathbf{2 8}$ 5583-5600, https://doi.org/10.1175/JCLI-D-14-00480.1.

Schurer, A. P., A. P. Ballinger, A. R. Friedman, and G. C. Hegerl, 2020: Human influence strengthens the contrast between tropical wet and dry regions. Environ. Res. Lett., 15, 104026, https://doi.org/10.1088/1748-9326/ab83ab.

Schwalm, C. R., S. Glendon, and P. B. Duffy, 2020: RCP8.5 tracks cumulative $\mathrm{CO}_{2}$ emissions. Proc. Natl. Acad. Sci. USA, 117, 19656-19657, https://doi.org/10.1073/pnas.2007117117.

Seidel, D. J., Q. Fu, W. J. Randel, and T. J. Reichler, 2008: Widening of the tropical belt in a changing climate. Nat. Geosci., 1, 21-24, https://doi.org/10.1038/ngeo.2007.38.

Seneviratne, S., and Coauthors, 2012: Changes in climate extremes and their impacts on the natural physical environment. Managing the Risks of Extreme Events and Disasters to Advance Climate Change Adaptation, Cambridge University Press, 109-230.

Seth, A., S. A. Rauscher, M. Biasutti, A. Giannini, S. J. Camargo, and M. Rojas, 2013: CMIP5 projected changes in the annual cycle of precipitation in monsoon regions. J. Climate, 26, 73287351, https://doi.org/10.1175/JCLI-D-12-00726.1.

Sillmann, J., V. Kharin, X. Zhang, F. Zwiers, and D. Bronaugh, 2013a: Climate extremes indices in the CMIP5 multimodel ensemble: Part 1. Model evaluation in the present climate. J. Geophys. Res. Atmos., 118, 1716-1733, https://doi.org/10.1002/ jgrd.50203.

, V. V. Kharin, F. Zwiers, X. Zhang, and D. Bronaugh, 2013b: Climate extremes indices in the CMIP5 multimodel ensemble: Part 2. Future climate projections. J. Geophys. Res. Atmos., 118, 2473-2493, https://doi.org/10.1002/jgrd.50188.

Small, R. J. O., S. P. de Szoeke, and S.-P. Xie, 2007: The Central American Midsummer Drought: Regional Aspects and
Large-Scale Forcing. J. Climate, 20, 4853-4873, https://doi.org/ 10.1175/JCLI4261.1.

Song, F., L. R. Leung, J. Lu, and L. Dong, 2018: Seasonally dependent responses of subtropical highs and tropical rainfall to anthropogenic warming. Nat. Climate Change, 8, 787-792, https://doi.org/10.1038/s41558-018-0244-4.

$\mathrm{Su}, \mathrm{H}$., and Coauthors, 2017: Tightening of tropical ascent and high clouds key to precipitation change in a warmer climate. Nat. Commun., 8, 15771, https://doi.org/10.1038/ncomms15771.

Taylor, K. E., R. J. Stouffer, and G. A. Meehl, 2012: An overview of CMIP5 and the experiment design. Bull. Amer. Meteor. Soc., 93, 485-498, https://doi.org/10.1175/BAMS-D-11-00094.1.

Tegegne, G., A. M. Melesse, and T. Alamirew, 2020: Projected changes in extreme precipitation indices from CORDEX simulations over Ethiopia, East Africa. Atmos. Res., 247, 105156, https://doi.org/10.1016/j.atmosres.2020.105156.

Trenberth, K. E., 2011: Changes in precipitation with climate change. Climate Res., 47, 123-138, https://doi.org/10.3354/cr00953.

Van Vuuren, D. P., and Coauthors, 2011: The representative concentration pathways: An overview. Climatic Change, 109, 5-31, https://doi.org/10.1007/s10584-011-0148-z.

Wang, B., C. Jin, and J. Liu, 2020: Understanding future change of global monsoons projected by CMIP6 models. J. Climate, 33, 6471-6489, https://doi.org/10.1175/JCLI-D-19-0993.1.

— Bull. Amer. Meteor. Soc., 102, E1-E19, https://doi.org/10.1175/ BAMS-D-19-0335.1.

Yang, W., R. Seager, M. A. Cane, and B. Lyon, 2015: The annual cycle of East African precipitation. J. Climate, 28, 2385-2404, https://doi.org/10.1175/JCLI-D-14-00484.1.

Yin, J., P. Gentine, S. Zhou, S. C. Sullivan, R. Wang, Y. Zhang, and S. Guo, 2018: Large increase in global storm runoff extremes driven by climate and anthropogenic changes. Nat. Commun., 9, 4389, https://doi.org/10.1038/s41467-018-06765-2.

Zhang, X., L. Alexander, G. C. Hegerl, P. Jones, A. K. Tank, T. C. Peterson, B. Trewin, and F. W. Zwiers, 2011: Indices for monitoring changes in extremes based on daily temperature and precipitation data. Wiley Interdiscip. Rev.: Climate Change, 2, 851-870, https://doi.org/10.1002/wcc.147.

Zhao, T., and A. Dai, 2015: The magnitude and causes of global drought changes in the twenty-first century under a low-moderate emissions scenario. J. Climate, 28, 4490-4512, https://doi.org/ 10.1175/JCLI-D-14-00363.1.

Zhou, L., H. Chen, and Y. Dai, 2015: Stronger warming amplification over drier ecoregions observed since 1979. Environ. Res. Lett., 10, 064012, https://doi.org/10.1088/1748-9326/10/6/ 064012. 